\title{
ABSTRACTS AND NOTICES
}

\author{
FROM THE \\ SCIENTIFIC AND TECHNICAL PRESS
}

\begin{abstract}
Issued by the
Directorates of Scientific Research and Technical Development, AIR MINISTRY
\end{abstract}

(Prepared by R.T.P.)

No. 39. September, 1936 .

A Simple Method for Calculating Stream Functions. (H. Steuding, Z.A.M.M., Vol. 16, No. I, Feb., 1936, pp. 20-22.) (I730 Germany.)

The author shows how the stream function of a domain of variable position and shape can be calculated by means of con-formal representation.

The paper thus forms a useful extension of the classical case of the elliptic cylinder treated by Lamb. (Textbook of Hydrodynamics.)

On the Stability of Double Row Vortices in a Rectangular Channel. (I. Isao, Comp. Rend., Vol. 202, No. 23, 8/6/36, pp. 1908-1910.) (i803 France.)

The following conclusions apply to the double row of vortices of unequal strength:-

1. Two configurations are possible, one symmetrical, the other staggered.

2. The symmetrical arrangement is always unstable, the sign of the vortices being opposite in the two rows.

3. The alternate arrangement is unstable if the sign of the vortices is the same in the two rows.

Influence of Fluid Boundaries on the Aerodynamic Characteristics of Wing Surfaces. (A. Toussant and S. Pirko, Comp. Rend., Vol. 202, No. 23, 8/6/36, pp. 1911-1914.) (1804 France.)

In two previous publications (pp. $1753^{-1} 75^{6}$ and pp. $1834-1836$, Comp. Rend., Vol. 202), the authors have investigated by the method of images, the boundary effects of guided and free jets respectively. The present paper deals with experimental confirmation of the calculated effects.

The wing tested had a maximum thickness of $4 \mathrm{~cm}$., chord $18 \mathrm{~cm}$. and span $83 \mathrm{~cm}$. The width of the fluid jet was $22 \mathrm{~cm}$. By applying calculated correction to the angle of incidence, satisfactory agreement of the experiments with those obtained in an infinite fluid was obtained, provided the angle of incidence was not large. 
Wave Resistance: The Mutual Action of Two Bodies. (T. H. Havelock, F.R.S., Proc. Roy. Soc., Vol. I55, No. 886, I/7/36, pp. 460-47I.) (I849 Great Britain.)

A new method is given for calculating wave resistance from the source distribution equivalent to the body producing the waves. Results are obtained for a simple case representing two small spheres in various relative positions. With the two spheres in the line of motion, the resistances differ by certain forces of action and reaction and also by the wave interference effects, which are assigned entirely to the following sphere.

Taking the two spheres abreast, the results are interpreted as showing the effect of a vertical wall upon the resistance of a sphere.

Finally, with the spheres in any relative positions, it is shown that effects of wave interference occur when the following sphere lies within the wave pattern produced by the leading sphere, and arise from both the transverse waves and the diverging waves.

A Note on the Measurement of Total Head and Static Pressure in a Turbulent Stream. (S. Goldstein, Proc. Roy. Soc., Vol. I55, No. 886, I/7/36, pp. 570-575.) (1850 Great Britain.)

If $p$ is the true mean static pressure, $q$ the resultant mean velocity, and $q_{1}$ the resultant turbulent velocity, it is proved that a total head tube in a turbulent stream measures $p+\frac{1}{2} \rho q^{2}+\frac{1}{2} \rho q_{1}{ }^{2}$. Reasons are given for assuming that if the turbulence is isotropic a static pressure tube measures $p+\frac{1}{6} \rho q_{1}{ }^{2}$.

On the Static Pressure in Fully Developed Turbulent Flow. (A. Fage, Proc.

Roy. Soc., Vol. 155, No. 886, 1/7/36, pp. 576-596.) (1851 Great Britain.)

The relation between the reading of a static pressure tube $(S)$ and the true average static pressure $(\vec{p})$ is expressed in the form

$$
S=\vec{p}+K \rho\left[\overline{v^{2}}+\bar{W}^{2}\right] \text {, }
$$

where $v$ and $w$ are the cross components of the turbulent velocity, and $K$ has a characteristic value for the same tube in turbulent streams of the same kind. The values of $K$ obtained for a static tube of common design ( 12 holes spaced $30^{\circ}$ ) were 0.28 (circular pipe) and 0.22 (rectangular pipe).

Information has been obtained on the relation between the values of $\vec{p}$ and $\rho \bar{q}^{2}$ (where $\bar{q}^{2}=\bar{u}^{2}+\bar{v}^{2}+\bar{w}^{2}$ ) in the turbulent wake behind a long circular cylinder.

The sum of the values $\bar{p}$ and $\frac{1}{2} \rho \bar{q}^{2}$ was equal to the pressure just outside the wake, and it is concluded from this result, and the known nature of the distributions of $\bar{p}$ and $\frac{1}{2} \rho \bar{q}^{2}$, that $\left(\bar{p}+\frac{1}{2} \rho \bar{q}^{2}\right)$ is constant across the wake.

Note on the Gliding of a Plate on the Surface of a Stream. (A. E. Green, Proc. Camb. Phil. Soc., Vol. 32, Part 2, 1936, pp. 248-252.) (I9r5 Great Britain.)

This note deals with the complete solution of the two-dimensional gliding of a plane plate on a stream of infinite depth. The results are expressed in terms of the actual length of the plate and hold for any angle of incidence.

In a previous solution by Wagner (Z.A.M.M., Vol. 12, No. 4, Aug., 1932, pp. 193-215, in course of translation) the spray is assumed parallel to the plate, in which case the lift increases linearly with the spray thickness. In the present solution, the direction of the spray alters with its thickness, the lift at first increasing and then decreasing to the limiting value of the classical Rayleigh flow (plate in infinite stream). 
The Formation of Shock Waves in Aerodynamic Fields at Boundary Velocities Below the Velocity of Sound. (L. Gabeaud, Comp. Rend., Vol. 201, No. 27, 30/12/35, pp. I460-1461.) (I935 France.)

The author has previously obtained a value for the depression existing on the base of a projectile in flight in term of the velocity of the air $V$ at the edge. Combining this with the condition of adiabatic flow, it follows that $V$ becomes equal to the local speed of sound when the velocity at infinity $=0.86$ local velocity of sound.

Experimental resistance figures obtained for shells show a discontinuity round about this figure.

A Numerical Expression for the Turbulence of Wind Channels. (A. Foch, Comp. Rend., Vol. 201, No. 27, 30/12/35, pp. 1462-1463.) (1936 France.)

The author proposes to record rapid pressure fluctuation by exposing an electrostatic microphone (suitably rectified) to the air current. From the reading so obtained, the amount due to sound only is subtracted and the remainder expressed as a percentage of the dynamic head. The difficulty is to obtain correct response over the large frequency range (10 to 500 second).

Experiments with hot wire instruments are in progress.

Movements of Contaminated Surfaces. (R. Merigoux, Comp. Rend., Vol. 202, No. 25, 22/6/36, pp. 2049-205I.) (194I France.)

Two photographs are shown of waves on the surface of "clean" and "contaminated" water respectively (in the latter case a trace of oleic acid has been added). Both surfaces show capillary ripples preceding the wave proper.

In the case of the clean surface, these ripples originate at the wave front. In the case of the oily surface there exists a considerable gap of smooth surface between the two sets of waves.

The phenomenon is associated with the friction between the monomolecular layer and the supporting liquid and is being studied quantitatively.

A Method of Estimating the Aerodynamic Effects of Ordinary and Split Flaps of Airfoils Similar to the Clark Y. (H. A. Pearson, N.A.C.A. Tech. Note No. 571, June; 1936.) (1946 U.S.A.)

An empirical method is given for estimating the aerodynamic effect of ordinary and split flaps on airfoils similar to the Clark $Y$. The method is based on a series of charts that have been derived from an analysis of existing wind tunnel data. Factors are included by which such variables as flap location, flap span, wing aspect ratio, and wing taper may be taken into account. A series of comparisons indicate that the method is suitable for use in making preliminary performance calculations and in structural design.

Some Problems on Aerodynamics of an Aeroplane with Split Flaps. (A. Martinov, Aeron. Eng. (U.S.S.R.), No. 6, June, 1936, pp. 1 3-32. Available as Translation No. 335.) (1954 U.S.S.R.)

The following are the main conclusions :-

I. With $V_{\min }=$ const. the speed range is a function of the cube root of $C y_{\max }$. Hence the effect of any further increase of $C y_{\max }$ produced in any way will become continuously less with respect to an increase in the speed range.

2. A cut-out in the middle section of the rear flap causes a much greater loss of effectiveness than cut-outs of the same size at the end of the wing.

3. The relative thickness of the wing profile has the greatest infuence with respect to the increase of the $C y_{\max }$ of a wing with rear flaps.

4. The slope of the flow in the region of the tail unit behind a wing with displaced rear flaps is greater than that calculated by the formula of Mogilevski 
and Ostoslavski. The higher the tail unit is set on the aeroplane the less difference there is between the calculated and the experimental results.

An Analysis of the Influence of Drag on Speed of Modern Transport Aeroplanes. (F. S. Chamberlin, Aero Digest., Vol. 29, No. I, July, 1936, pp. 26-28.) (202 I U.S.A.)

The outstanding means of improving speed performance are :-

(a) Better lift increasing devices so that higher wing loading can be used.

(b) Increased taper of wing.

(c) Full retraction of landing gear and tail wheel.

(d) Improvement in fuselage streamlining (retractable wind shield).

(e) Development of engines suitable for installation inside the wing (Junkers horizontally opposed piston engine).

Supersonic Wind Tunnel at Guidonia. (Inter Avia., No. 340, 9/7/36, p. 6.) (2049 Italy.)

The tunnel section is $40 \times 40 \mathrm{~cm}$. and maximum speed is $638 \mathrm{~m} . / \mathrm{sec}$. $\left(\mathrm{r}, 44^{\circ}\right.$ m.p.h.). The air current is produced by an axial blower $(3,910$ r.p.m.) absorbing 2,900 b.h.p. The tunnel is sealed against the external atmosphere and air densities can be adjusted to cover the range ground to 90,000 feet altitude. The flow is rendered visible by proper illumination and the shock wave at a model wing occurring at an air speed of $\mathrm{I}, \mathrm{I}$ (0) m.p.h. is illustrated.

Preliminary Report of Tests on "Pou du Ciel" at Chalais-Meudon. (Les Ailes, No. 787, I $7 / 7 / 3^{6}$, p. I I.) (2051 France.)

If dived beyond a certain angle the machine becomes unstable, oscillates and turns on its back. These phenomena cannot be prevented by any control movement of the pilot. Experiments are being continued to study what modifications, if any, of design variables will obviate this danger. Stability in horizontal flight and when climbing appear to be satisfactory.

Body and Tail Moments in Spin. (H. B. Irving, Airc. Eng., Vol. 8, No. 9o, August, 1936, pp. 221-222.) (2339 Great Britain.)

In a previous article by Korvin-Kroukosky (Airc. Eng., Vol. 5, May, I933, pp. 105-I12) the view was expressed that during a flat spin, the body and tail were largely shielded by the wings.

The author shows that this is erroneous. The tail plane is responsible for the blanketing and even reversal of the fin and rudder. The body, far from working ineffectively in a wide wake behind the stalled wings, will provide a very important control, provided it is of suitable shape and dimensions.

The shielding of the fin and rudder by the tail plane can be governed by :-

(I) Positioning of tail plane.

(2) Fin and rudder shape.

Estimation of Moments of Inertia of Airplanes from Design Data. (H. W. Kirschbaum, N.A.C.A. Tech. Note No. 575, July, 1936.) (2371 U.S.A.)

A method of determining the moments of inertia of an airplane from design data of the weights and locations of the component parts is described. The computations required to ascertain the centre of gravity position are incorporated with the calculations of moments of inertia. A complete set of data and calculations for a modern airplane is given to illustrate the procedure. From a comparison between calculated and measured values it is believed that the moments of inertia can be estimated-within ro per cent. by the use of this method. 
Wing Fuselage. Interference. (A. L. Boyajian, Aero Digest., Vol. 29, No. 2, August, 1936, pp. 28-30.) (2419 U.S.A.)

Wind tunnel measurements were carried out on a low wing monoplane with tapered wing roots and were compared with those for conventional wing root construction, both filleted and unfilleted. The experiments show that a reduction in wing chord (symmetrical taper) is beneficial and produces higher lift and better flow up to angles of incidence of $7^{\circ}$. An explanation is given on boundary layer theory (induced lift).

Contribution to the Problem of Airfoils Spanning a Free Jet. (J. Stüper, L.F.F., Vol. 12, No. 8, 25/12/35. Translation N.A.C.A. Tech. Memo. No. 796, June, 1936.) (2632 Germany.)

After a brief discussion of previous work on an unwarped wing of constant chord spanning a free jet, the computation of the circulation and lift distribution for different forms of warped wings spanning rectangular and circular jets was carried out. The computed values are compared with test values and the agreement is found to be good. The effect of placing the wing eccentrically is slight and a suitable correction factor has been worked out.

Flow Phenomena on Plates and Airfoils of Short Span. (H. Winter, V.D.I. (Special Issue) (Aviation), I936. Translation, N.A.C.A. Tech. Memo. No. 798, July, 1936.) (2634 Germany.)

Investigations on the flow phenomena round plates and cambered wings were carried out with the aid of force measurements, some pressure distribution measurements and photographic observation.

The experimental methods are described. The results show how nearly the lift line and lift surface theories agree with the experiment.

Scale Effect in Tank T'ests of Seaplane Floats. (R. Schmidt, L.F.F., Vol. 13, No. $7,20 / 7 / 36$, pp. 224-237.) (2638 Germany.)

Experiments were carried out on two models (scale $1 / 2.5$ and $1 / 5$ ) and compared with full-scale measurements obtained with a special three component balance.

The comparison shows that the float model should possess at least a scale of $\mathrm{I} / 2.5$ so as to ensure satisfactory agreement with practice. (Twelve references.)

Smoothing Out Waves of the Sea. (Soviet Institute of Water Transport.) (J. Am. Soc. Nav. Eng., Vol. 48, No. 3, August, 1936, pp. 447.) (2693 U.S.S.R.)

A series of parallel pipes carrying compressed air are submerged to a depth of some 30 feet beneath the surface of the water. Each pipe, 4 inches in diameter, is perforated with small holes several inches apart. When a wave passes over the apparatus, the jets of compressed air released through the perforations are stated to smooth the water surface.

With the use of strong " columns" of compressed air it is contended that a large wave could be completely levelled.

Tests with a "wave-breaker" in the harbour of Sebastopol (Black Sea) are reported to have shown that waves 3 or 4 feet in height could be reduced in force and height by 40 per cent. The "crests" were entirely smoothed out.

An application to flying boat harbours is contemplated. 
A Simplified Application of the Method of Operators to the Calculation of Disturbed Motions of an Airplane. (R. T. Jones, N.A.C.A. Report No. 560, 1936.) (2799 U.S.A.)

The method is applied to the rolling motion produced by deflecting ailerons at low speed and sideslipping during two control turns respectively.

The airplane assumed in these calculations is a typical two-seater monoplane of $\mathrm{I}, 60 \mathrm{olb}$. gross weight.

On the Mapping of the Velocity Potential and Stream Functions of an Ideal Fluid. (A. C. Erickson, Science (U.S.A.), Vol. 81, No. 2098, 1.5/3/36, pp. 274-275.) (28I6 U.S.A.)

The writer describes a modification of the electrolytic method described by Relf (Phil. Mag., 48, 535, 1924). In place of the liquid electrolyte, sheets of conducting black silhouette paper are used, and the earphone and alternating current of Relf are replaced by a galvanometer and direct electric current.

Velocity potential lines about an aerodynamic form are obtained by cutting out the corresponding shape from the centre of the conducting sheet.

The streamline flow about a form can be plotted directly by cutting out the shape in a highly conducting material and placing it on the conducting paper, making certain that good contact is obtained.

Lead pencils can be used as electrodes and in this way the pattern is obtained directly on the paper for record purposes.

When quantitative accuracy is required, the paper is replaced by a more homogeneous material, such as stainless steel $\frac{1}{32}$-inch thick.

The Flow Around a Plane Wing with Aileron. (C. Schmieden, Z.A.M.M., Vol. 16, No. 4, August, 1936, pp. 193-198.) (2818 Germany.)

Wing and aileron being represented by two segments of straight lines, the author maps the exterior of this contour on a half-plane by starting from a special case of flow around it. The resultant and the moment of the air forces are then calculated by means of Blasius' formulæ.

Determination of the Air Forces on a Plane Wing with Aileron. (G. Ellenberger, Z.A.M.M., Vol. 16, No. 4, August, 1936, pp. 199-226.) (2819 Germany.)

The forces acting on a plane wing with aileron in non-stationary motion are determined taking into account the vortices breaking away from the trailing edge. To this purpose, the author calculates the velocity potential for the most general movement of the wing, which, by known formula, yields the air forces on the wing. Applications are made to the most general movement of a wing without aileron and to the stationary motion and the harmonic oscillations of a wing with aileron.

The Flow of a Fluid Streaming into a Straight Pipe of Annular or Circular CrossSection. (W. Muller, Z.A.M.M., Vol. I6, No. 4, August, 1936, pp. 227-238.) (2820 Germany.)

When a viscous fluid streams into a narrow tube with cylindrical walls, there ensues an initial non-stationary motion which finally leads to the stationary Poiseuille flow. The author represents this motion analytically by means of an exact integral of the Stokes-Navier equations and studies it for different conditions of pressure.

The Destruction of Materials by Fluid Impact and Cavitation. (J. Ackaret and P. de Haller, Institut für Aerodynamik, E.T.H. Zurich, Sept., r936.) (282 I Switzerland.)

In a recent paper (Z.V.D.I., II/7/36, p. 863) Messrs. Schwarz and Mantel stipulate the existence of hydraulic pressures of the order of $10,000 \mathrm{~kg} . / \mathrm{cm} .{ }^{2}$ in order to account for the observed destruction. 
Direct pressure measurements (piezo electric) by the authors have failed to record pressures exceeding $1, \infty 00 \mathrm{~kg} . / \mathrm{cm} .{ }^{2}$. The objection raised that these experiments failed to record peak pressures of short duration has been met by new experiments in which the immersed material is subjected to blows of a pneumatic hammer, the pressure being transmitted by a close fitting piston.

In the case of cast iron, corrosion became marked after 90,000 blows (two hours), although there is absence of gas bubbles and the liquid (water or paraffin) is chemically inactive.

The authors suppose that the destruction is due to variation of transmission speed of compression wave in the material brought about by heterogeneous nature of the surface.

Variation of orientation of crystals will cause large differences in local stresses which ultimately cause the surface crystals to break loose. This applies especially to graphite in cast iron.

Air Pressure on Chimney Stacks of Circular Section. (J. Ackaret, Institut für Aerodynamik, E.T.H. Zurich, Sept., 1936.) (2822 Switzerland.)

It is well known that the resistance coefficient of smooth circular cylinders depends very markedly on Reynolds number and diminishes rapidly between $R_{\mathrm{e}}=0.15 \times 10^{6}$ and $R_{\mathrm{c}}=0.35 \times 10^{\mathrm{B}}$.

The author shows that in the practical case of rough cylinders (bricks and mortar) the reverse is the case, the resistance coefficient increasing over the range $R_{\theta}=0.1$ to $\mathrm{I} \times 10^{6}$.

The wind loading in practice is thus practically double that calculated from smooth cylinder tests.

Experimental Study of the Scour of a Sandy River Bed by Clear and by Muddy Water. (C. A. Wright, Bur. Stan. J. Res., Vol. I7, No. 2, August; 1936, pp. 193-206.) (2835 U.S.A.)

An experimental comparison was made of the scour produced in a bed of fine sand by muddy and clear water respectively. The object was to stimulate conditions existing in the Colorado River at the Boulder Dam before and after construction.

Critical velocities of the water were determined for incipient movement of the sand bed and were found to be greater by ro per cent. for muddy water containing clay in suspension, than for clear water.

It is concluded that the clear water discharged at the Boulder Dam will cause greater scouring than the original river (without the dam).

The Effect of Side Wind on the Path of Projectile Fired from Aircraft. (P. de Valroger, Rev. de l'Arm. de l'Air, No. 85, Aug., 1936, pp. 850-862.) (2880 France.)

For speeds at present in use, the aerodynamic forces on the bullet are negligible. Observation of the smoke track of tracer bullets is apt to lead to erroneous conclusions as to actual flight path of bullet.

The normal shaped bullet will only lose stability at cross wind speeds approaching the velocity of sound. The type of motion then occurring will require further experimental investigation (spinning shell in supersonic wind aunel).

On the Origin and Suppression of the Discontinuity in the Hydrodynamic Resistance of Seaplane Floats. (G. Sabathe, Comp. Rend., Vol. 202, No. 22, 2/6/36, pp. 1836-1838.) (289o France.)

The observed discontinuity is usually associated with an increased influence of the frictional resistance (see N.A.C.A. Tech. Memos. No. 735 and 739). Model experiments show that there exist under these conditions regions of negative 
pressure and partial cavitation on the lower float surface, especially in the neighbourhood of the step. This depression was relieved by allowing the back of the step to communicate with the atmosphere through a narrow channel (12 $\mathrm{mm}$. wide). By this means the resistance of the float was reduced up to 25 per cent.

Effect of Reynolds Number and Turbulence on the Maximum Lift Coefficient of an Aerofoil. (P. Krasischikov, Trans. C.A.H.I., No. 268.) (2893 U.S.S.R.)

Wind tunnel measurements were carried out on $C_{a}$ max. for the following profiles :-

$$
\begin{aligned}
& \text { R.A.F. 28, 38, 48, } 34 . \\
& \text { Clark YH. } \\
& \text { Göttingen } 3^{87} \text {. }
\end{aligned}
$$

The profiles were divided into the following four groups :-

(I) Symmetrical and thin profiles.

(2) Medium thickness and small curvature.

(3) Thick profiles and average curvature.

(4) Sharp leading edge.

The effect of increasing $R_{\mathrm{e}}$ (at small turbulence) on $C_{\mathrm{a}}$ max. differs for the groups :-

(I) $C_{\mathrm{a}}$ max. increases rapidly.

(2) $C_{\mathrm{a}}$ max. diminishes slowly.

(3) $C_{a}$ max. diminishes more rapidly.

(4) $C_{a}$ max. increases very slowly.

Increasing the turbulence increases the effect in group $I$ and changes the sign of $d C_{\mathrm{a}}$ max. $/ d R_{\mathrm{c}}$ for groups $2-4$.

Design, Construction and Efficiency of Wind Tunnels. (S. Hoerner, Z.V.D.I., Vol. 80, No. 32, 8/8/36, pp. 949-957.) (2894 Germany.)

Various types of construction (German, French and English) are described and the increasing popularity of the free jet tunnel is noted.

The efficiency of the tunnel is sometimes defined as the ratio of the driving horse-power to air horse-power in the measuring section.

Since a considerable proportion of the jet kinetic energy is reconverted into pressure energy and thus returned to the blower, the above ratio is generally less than unity and can be as low as one-third.

Taking this figure, the power consumption of any tunnel can be given as

where $F=$ cross section of jet in $\mathrm{m}^{2}$.

$$
\rho v^{3} F /(6 \times 75) \text { b.h.p., }
$$

$\rho=$ density of air in $\mathrm{kg}$. $\mathrm{sec}^{2} / \mathrm{m}^{4}$.

$v=$ air speed in $\mathrm{m} . / \mathrm{sec}$.

At constant speed, the b.h.p. thus varies directly as the area of the jet and ranges from 300 b.h.p. for $7 \mathrm{~m}^{2}{ }^{2}$ (normal research type) to $2, \infty 00$ b.h.p.

(R.A.E. 24 -foot channel $=42 \mathrm{~m}^{2}$ )

4,500 b.h.p. (Chalais-Meudon $=100 \mathrm{~m} \cdot{ }^{2}$ )

and 6,000 b.h.p. (N.A.C.A. full-scale $=150 \mathrm{~m} \cdot{ }^{2}$ ).

The article gives an interesting account of air vibrations in tunnels and the method of cure (spoilers in nozzle and slots in receiver or tunnel).

The amount of turbulence in the tunnel air affects the measurements in certain cases and the method of detection and correction is explained (Twenty-six references.) 
The Lift and Minimum Induced Drag of a Wing in the Neighbourhood of the Ground. (P. de Haller, Proceedings of Institute of Aerodynamics, Zurich, No. 4-5.) (2896 Switzerland.)

The theoretical investigation shows that the ground effect is complex.

In the case of a thin profile of infinite span, at angles of incidence greater than $15-16^{\circ}$, the presence of the ground diminishes the lift. If the angle of incidence exceeds $15^{\circ}$, the lift at first diminishes and then increases as the wing approaches the ground. The effect is less marked in the case of large wing curvature.

In the case of finite span, the ground effect reduces the induced drag and the effective angle of incidence is thus altered. There is a tendency for the lift to concentrate near the centre of the wing. In practice, the utilisation of a wing is limited by breakaway of flow on the suction side.

The effect of this on the problem can only be determined experimentally. (Nine references.)

Pressure Drop in a Pipe with Geometric Roughness. (L. Schiller, Forschung, Vol. 7, No. 3, May-June, 1936, pp. 154-155.) (I926 Germany.)

After a general review of the problem, special attention is given to the work of $V$. Streeter (frictional resistance) in artificially roughened pipes (Proc. American Soc. Civil Eng., Vol. 61, 1935, p. 163). This author investigated the effect of screw threads of same depth, but various shapes and pitches. Of interest is a determination of the size of sand grains yielding the same resistance coefficient as the screw thread. In the case of the threads $0.6 \mathrm{~mm}$. deep, the equivalent grain has a diameter of $2.5 \mathrm{~mm}$., whilst for very shallow threads $(0.13 \mathrm{~mm}$.) the equivalent grain is only $0.04 \mathrm{~mm}$. It is probable that in the case of shallow threads, the flow is still in a critical stage and the quadratic law not fully established.

Engine Nacelles and Propellers and Airplane Performances. (D. H. Wood, J.S.A.E., Vol. 38, No. 4, April, 1936, pp. 148-160.) (1 172 U.S.A.)

This article is a review of some 15 reports, mainly N.A.C.A.

Part $I$ deals in detail with cowled radial air-cooled engines placed in various positions relative to the wing. Part II considers the case of the liquid-cooled engine, whilst some other possibilities are dealt with briefly in Part III.

PART 1.-In estimating the relative order of merit of various nacelle-propelleraeroplane combinations the following factors are utilised :-

(a) Propulsion efficiency.

(b) Nacelle drag factor.

(c) Net nacelle-propeller efficiency $=a-b$.

(a) This is defined as the proportion of total engine b.h.p. available for overcoming the drag of the aircraft without nacelles, after allowance for increased drag due to propeller slipstream has been made.

The propeller losses $(\mathrm{I}-a)$ thus include this extra drag. At a given speed (a) depends on $V / n D$, pitch angle, type and position of nacelle as well as on the speed factor $C=\left(\rho V^{s} / P n^{2}\right)$, where

$$
\rho=\text { density, } V=\text { speed, } n=\text { r.p.m. and } P=\text { b.h.p. }
$$

(b) This is defined as proportion of total engine b.h.p. required to overcome nacelle drag, including interference drag, but excluding slipstream effects.

For radial engine installations the best position of the cowled nacelle is ahead of the leading edge of the wing, the fairing terminating at approximately one-haif the wing chord.

Denoting such a nacelle position as $A$, the following table gives the improvement in factors $a, b$ and $c$, compared with an uncowled nacelle placed below the 
wing (position $B$ ). Case $C$ in the table refers to an obsolete type of aircraft with nacelle in $B$ position and gives a measure of the total improvement over the last seven years.
(a) Propulsion efficiency
... $\quad$ A $\quad 84 \%$
B
C
(b) Nacelle drag factor...
… $\quad \ldots \quad$ I $3 \%$
(c) Net nacelle-propeller efficiency $\ldots 7 \%$ Speed (m.p.h.)
... 194

$\begin{array}{rr}80 \% & 74 \% \\ 39 \% & 28 \% \\ 41 \% & 46 \% \\ 156 & 128\end{array}$

It will be noticed that improved cowling and better location of nacelle relative to rest of aeroplane has resulted in a 25-30 per cent. gain in effective b.h.p., the corresponding gain in speed depending on the type of aircraft.

On the assumption that the nacelle drag varies as (engine diameter) ${ }^{2}$, the factor $(c)$ can be obtained on a speed basis for a series of engines of different diameter, power and operating speeds. Obviously, the smallest diameter engine giving the requisite power is best suited for high speed work (multi-row radial). At the present moment small diameter is usually associated with small power output and a multiplicity of such engines, although individually of small drag, are unable to propel a machine at high speed unless the propeller characteristics are favourable. This can only be achieved by the use of either variable gear or variable pitch airscrew, which thus assume special importance in this case.

In the reports so far published no reference is made to in-line engines. Experience with these has so far been mainly limited to small power outputs, and according to the author there is no evidence that such engines can be more efficiently cowled than radials of equivalent power. In the case of large power units, the available evidence definitely points to increasing cowling and cooling difficulties in the in-line engine compared to the corresponding radial.

PART II.-The highest power output in a single unit has so far been achieved by a boosted liquid-cooled engine. All the difficulties in this design are here concentrated on the radiators (engine and oil). At 200 m.p.h. the combined nacelle-radiator drag of the best Prestone cooled installations is of the order of I 2-I 5 per cent. of the total drag. This is practically the same figure as for aircooled radialș.

It appears probable that the radiator drag can be reduced by cowling (see Abstract No. 39/58). No figures are, however, available. It is essential that such experiments reproduce inflow conditions as existing in practice. Departure from this has rendered most of the past experimental work useless.

PArT III.-If the engine could be housed entirely within the wing, the need for a separate nacelle would not arise. The need of extension shafts together with the possibility of dangerous resonance vibrations between wing and shaft supports has, however, to be considered.

Experiments of the author show that the following wing-propeller efficiencies can be realised in the case of a pusher propeller.

$\begin{array}{ccc}\begin{array}{c}\text { Forward speed } \\ \text { (m.p.h.) }\end{array} & \begin{array}{c}\text { Propulsion efficiency } \\ \text { (engine inside wing) }\end{array} & \begin{array}{c}\text { Nacelle/propeller } \\ \text { efficiency } \\ \text { (best radial } \\ \text { iıstallation) }\end{array} \\ \text { 180 } & 90 \% & 78 \% \\ 240 & 85 \% & 71 \% \\ 300 & 75 \% & 55 \%\end{array}$

The differences in favour of engine installed inside the wing are thus very marked at high speeds, provided that there is no additional drag due to radiators.

An obvious solution is the skin radiator, which has been used already in some racing machines. It is hoped that work will concentrate on this design so as to improve its reliability. 
Eleventh Annual Aircraft Research Conference. (M. Watter, Aero Digest., Vol. 28, No. 6, June, 1936, pp. 48-50 and 84.) (1725 U.S.A.)

Points of interest :-

I. A new high speed wind tunnel has been constructed for the N.A.C.A. at Langley Field, 8 feet diameter working section, maximum speed 500 m.p.h. produced by 8,000 b.h.p. electric motor driving 16 feet diameter i 8-bladed fan propeller.

2. Deleterious effects of rivet heads on surface friction. Possibility of improved take-off performance of flying boats by suppression of exposed rivet on submerged part of hull.

3. New N.A.C.A. cowl incorporating spinner and guided air escape.

4. Renewed interest is shown in hydro-vanes as a means of improving the later stages of " unsticking."

5. Premature tip-stall of tapered wings can be prevented by increase of camber towards the top.

6. For air-cooled engine cylinders, a fin spacing of 12 per inch is recommended for the standard fin of $\frac{1}{4}$ inch depth.

7. Single cylinder Diesel engine, 5-inch bore, 6-inch stroke, 2,000 r.p.m., zoolb. per square inch break mean effective pressure at Iolb. square inch boost was demonstrated.

8. The external airfoil is considered the best take-off (high lift) device, since drag increase is small compared to split flap.

A Mathematical Contribution to the Theory of Vibration in Wings. (V. Borbely, Z.A.M.M., Vol. 16, No. I, Feb., 1936, pp. I-4.) (1729 Germany.)

Four integrals that appear in the theory of vibrating wings are evaluated in finite form by means of Bessel functions.

Wind Tunnel Investigation of Ordinary and Split Flaps on Airfoils of Different Profile. (C. J. Wenzinger, N.A.C.A. Report No. 554, 1936.) (I740 U.S.A.)

Conclusions :-

1. Full-span split flaps produced somewhat greater increases in $C_{\mathrm{L} \max }$ of the three airfoils tested than did full-span ordinary flaps of the same width, but the $L / D$ at $C_{\mathrm{L} \max }$ was practically the same for the two types of flap.

2. Based principally on the speed-range ratio $C_{\mathrm{L} \max } / C_{\mathrm{D} \min }$, the relative order of merit of the airfoils tested with either ordinary or split flaps is N.A.C.A. 23,or2, Clark Y, and N.A.C.A. 23,021 .

3. Any gap between the wing and the leading edge of ordinary flaps had a very detrimental effect on the $C_{\mathrm{I} \max }$ attainable.

4. The hinge moment coefficients of the full-span ordinary flaps were practically independent of flap chord; the actual hinge moments varied approximately as the square of the flap chord. Both of these findings accord with theory.

5. The hinge moment coefficients of the full-span ordinary flap were practically the same as those of split flaps of similar size.

Wind Tunnel Tests of the "Pou du Ciel." (Les Ailes, No. 783 , ז8/6/36, p. I I.) (I748 France.)

A model (size not stated) was tested in the Amsterdam wind tunnel. Comparison with similar tests carried out at Lodz (see Translation No. 306) and Issy Les Moulineaux shows that the stability (especially at small angles of incidencehigh speed) is largely controlled by the percentage overlap between the two wings. Thus at Lodz, with a 3 per cent. overlap, the stability is satisfactory at $3^{\circ}$ incidence. The Dutch tests (overlap I 3.8 per cent.) show insufficient stability at $6^{\circ}$ and definite instability at $3^{\circ}$. The wings had the same angle of incidence and the effect of gap has not so far been investigated. 
Attention should be called to the fact that in these model tests the controls are rigidly held.

Causes of Accidents. (E. L. Vidal, Inter Avia., No. 331, I 1/6/36, pp. 1-3.) (I 784 Switzerland.)

In U.S.A. aircraft passenger traffic the percentage of accidents is almost equally divided between error of judgment, power plant failure, structural failure, atmospheric influence and causes unspecified.

In the case of mail freight over one half of the accidents are due to errors of judgment, whilst nearly $3^{\circ}$ per cent. are due to power plant failures. The total number of accidents have decreased from II5 (in I932) to 62 (in I935). "According to the law of averages, a passenger could fly on American air lines 500 miles a day for 20 years without fatal injury. To-day he can fly 500 miles a day for 120 years."

Preliminary Tests in the N.A.C.A. Free-Spinning Wind Tunnel. (C. H. Zimmerman, N.A.C.A. Report No. 557, 1936.) (2736 U.S.A.)

Typical models and the testing technique used in the N.A.C.A. free-spinning wind tunnel are described in detail. The results of tests of two models afford a comparison between the spinning characteristics of scale models in the tunnel and of the airplanes that they represent.

The models are built of balsa wood and ballasted with lead to the proper mass distribution. A clockwork delayed action mechanism is mounted in the model to move the control surfaces during the spin.

The models of the $\mathrm{XN}_{2} \mathrm{Y}-\mathrm{I}$ and $\mathrm{F}_{4} \mathrm{~B}-2$ airplanes gave good approximations to the spinning characteristics of the airplanes, in both steady spins and recoveries. Since these models were scaled from somewhat similar biplanes, no conclusions are drawn as to the reliability of model results in general.

The Conquest of the Stratosphere (concluding article). (R. Bernson, Rev. de l'Arm. de l'Air, No. 85, Aug., 1936, pp. 888-9i6. For Part I, see No. 84, July, 1936, pp. 773-794.) (2882 France.)

A detailed description of the ascent of the American balloon Explorer II (Nov., 1935) where the record height of $21,700 \mathrm{~m}$. was reached.

The stratosphere balloon as designed at present was subjected to considerable stress concentration when only partly filled (ascending or descending). Suggestions by Prof. Picard and the U.S.S.R. Government concerning necessary modifications in order to reach greater heights are discussed.

The article is well illustrated.

Rate of Climb and Steepness of Flying Path. (C. Alippi, L'Aerotecnica, Vol. 16, No. 7, July, 1936, pp. 538-542.) (2844 Italy.)

The path of an aircraft for the quickest climb (highest rate of ascent) does not coincide with that for the steepest climb.

The former corresponds to an angle of incidence making $(\mathrm{Cw} / \mathrm{Ca})^{\mathbf{1}^{\circ} \mathrm{s}}$ a minimum.

The steepest climb has a slightly greater angle of incidence approximately half way between $C a$ max. and $(C w / C a)^{1 \cdot 5}$ min.

This angle of incidence does not only depend on aerodynamic constants but also on the size of the aircraft and especially on the excess power available.

Flight on Rotating Wings. (W. L. Le Page, J. Frank. Inst., Vol. 222, No. 3, Sept., 1936, pp. 255-288.) (2885 U.S.A.)

The historical section of this article is of interest in showing photographs of various helicopters in flight. With regard to the "direct control " autogiro, the view is expressed that the suppression of the fixed control surfaces has reduced aerodynamic efficiency. In spite of the undoubted success of the autogiro (including the latest development in jumping starts), the author is of the opinion 
that there exists a demand for the true helicopter. The principal causes of previous failures of this type of machine are classified as :-

(I) Failure to balance rotor torque.

(2) Excessive rotor disc loading.

(3) Inefficient utilisation of power.

(4) Mechanical complexity.

(5) Excessive weight and parasite drag.

(6) Gyroscopic precession in the rotor system.

(7) Instability and ineffective control.

Some of these are treated in detail. (To be continued.)

Parachutes with Variable Rates of Descent. (Flugsport, Vol. 28, No. 14, p. 347, and Inter Avia., No. 319, 30/4/36, p. 4.) (2892 U.S.S.R., France.)

Russian Experiments.-A valve operated by the pilot changes velocity of descent between 4 and $30 \mathrm{~m}$. $/ \mathrm{sec}$.

French Experiments.-The parachute known as the " Magnet" has no valve but is fitted with an annular sail along the rim. By means of an arrangement of ropes, the pilot can control the effective drag of the chute and thus the rate of descent.

Experimental Investigation on Wing Flutter. (H. L. Studer, Proceedings of Institute of Aerodynamics, Zurich, No. 4/5.) (2897 Switzerland.)

The model wings $40 \mathrm{~cm}$. span and $\mathrm{I} 2 \mathrm{~cm}$. chord were made of balsa wood (reinforced) and mounted so that they could execute torsional and transverse vibrations simultaneously. The most dangerous type of flutter is associated with a periodic variation in the type of air flow round the wing (so-called hysteresis effect of the stall).

If such vibrations start during a steep dive, the angle of incidence of the wing should be increased quickly and then slowly diminished. It is preferable not to proceed from a horizontal flight into a dive directly, but go through a so-called "tonneau" manœuvre first.

It has been observed in several cases where flutter developed and ultimately lead to a fatal accident that the pilot made no effort to save himself by parachute and did not even switch off the engine.

According to the author large amplitude vibrations of the type considered are likely to cause the pilot to lose consciousness in a short time.

Forty-one references.

Propulsion by Reaction without Utilisation of External Air. (N. A. Rinin, L'Aerotecnica, Vol. I5, No. 9-10, Sept.-Oct., 1935, pp. 912-9I4.) (333 Italy.)

Three kinds of rockets are considered :-

(1) Normal rocket, the thrust being obtained by the expulsion of products of combustion of the charge.

(2) Rockets which aspirate the external air in order to increase the thrust.

(3) Rockets which capture the external air in order to increase the combustion.

The thrust of (I) is given by $F=(u / g) c$,

where $u=$ weight of gas expelled per second.

$c=$ velocity of expulsion.

In order to obtain a large thrust, $u$ and $c$ must be large.

Methods for increasing $u$ and $c$ (type 3 ).

If $c^{\prime}=$ velocity of expulsion.

$a=$ additional mass of air captured in relation to products of combustion. 
The propulsion efficiency $\eta^{\prime}$ is given by

$$
\eta^{\prime}=\left(2 v c^{\prime}-v+v / a\right) /\left(c^{\prime 2}-v^{2}+2 v^{2} / a\right) \text {. }
$$

If $a=\mathrm{I}$, this reduces to the efficiency of the simple rocket

$$
\eta=(2 v / c) /\left(\mathrm{I}+v^{2} / c\right)
$$

This becomes a maximum $(=\mathrm{I})$ if $v=c$.

In the case of added air, it is necessary to obtain a relation between $c$ and $c^{\prime}$.

If all the thermal energy is transformed into kinetic energy

when $Q=$ calorific value.

$$
c^{\prime}{ }_{1}=9^{\mathrm{I}} \mathrm{V}^{\prime}\{Q /(\mathrm{I}+a L)\}
$$

$L=$ necessary weight of oxygen.

$a=$ excess coefficient.

If oxygen supplied pure, $a=\mathrm{I}$.

In the case of air $a=4 \cdot 33$.

The author considers the combustion of various hydrocarbons, either pure or mixed with metallic powders ( $\mathrm{Li}, \mathrm{Bo}, \mathrm{Al}$, etc.).

Maximum velocity is obtained with $\mathrm{H}_{2}(5,170 \mathrm{~m} . / \mathrm{sec}$.$) .$

Good results have been obtained with a mixture of petrol and oxygen in the ratio of $\mathrm{I}: 3.5$ by weight.

From the ideal velocity of expulsion, the author next passes to the practical case, where a portion only of the heat of combustion becomes available (thermal efficiency of cycle). This depends primarily on the expansion ratio.

If $p_{o}=$ pressure before final orifice in combustion chamber.

$p=$ back pressure.

$$
\eta t=\mathbf{I}-\left(p / p_{\mathrm{o}}\right)^{(\mathrm{k}-1) / \mathrm{k}}
$$

$p$ is not necessarily $=p_{a}$, the atmospheric pressure.

The exact solution is difficult, but some attempt has been made following the methods of Professor Macinski.

The general theory of rocket flight is next considered. Simplifying assumptions (constant air density, constant resistance coefficients, constant rate of discharge) have to be made and the author refers to a number of published works.

It is finally concluded that for great heights $(30 \mathrm{~km}$.) and high speeds $(800 \mathrm{~m} . / \mathrm{sec}$.) rocket propulsion is the only solution.

Radial Engines Manufactured by Gnome-Rhone (France). The K.14 and NO-14. (Les Ailes, No. $78_{3}, 18 / 6 / 36$, p. 4.) (1750 France.)

According to statements by the firm, approximately 2,000 K. I 4 engines are in daily service. It is admitted that as a result of inadequate cooling, fairly frequent decarbonisation is required. This depends on the types of cowling fitted. The old type of cowling as fitted to the Bloch and Amiot are unsatisfactory (decarbonisation time jo hours). Savoia-Marchetti have developed a satisfactory cowling for this type of engine and similar designs are now being fitted to the Potez PZL, Loire 46 and Amiot (overhaul time extended to 200 hours).

American type, controlled pressure cowling is now being tried on the Bloch 200 . As a result of experience gained (60,000 flying hours), a new (1937) K. I4 has been brought out, known as NO-I4. The cooling fin area has been increased from 18 to $25 \mathrm{dm} .^{2}$ per litre of stroke volume and more fins have been fitted to the cylinder base. The cylinder is nitrated and sodium-cooled valves are fitted. The supercharger drive has been strengthened so as to enable greater boost pressure.

The new NO-I 4 will be rated at $95^{\circ}$ b.h.p. at 4,000 metres. It is stated that ultimately all the 2,000 K. I4 in service will be renovated to conform to NO-I4 specifications, at a cost of 90,000 francs per engine. The author quotes French Press opinions questioning the policy of designing air-cooled radials of the two-bank type of such large power output and thinks that the alternative watercooled design required further study. 
Stroboscope for Synchronising Engine. Revolutions in Multi-Engine Aircraft. (Aviation, Vol. 35, No. 6, June, 1936, p. 45.) (1760 U.S.A.)

Inside a casing is a disc driven by the central engine. This disc is illuminated by two neon lamps actuated by the ignition system of the two engines. The disc is fitted with a number of radial marks depending on type of engines and by regulating the speed of the two outboard engines till the disc appears stationary, all three engines can be synchronised.

Boosted Performance of a Compression-Ignition Engine with a Displacer Piston. (C. S. Moore and H. H. Foster, N.A.C.A. Tech. Note No. 569, May, 1936.) (1869 U.S.A.)

The engine operation under boosted conditions was very smooth, there being no combustion shock even at the highest maximum cylinder pressure (I, I5O pounds). Indicated mean effective pressures of 240 pounds per square inch for fuel consumptions of 0.39 pounds per horse-power-hour have been readily reproduced during routine testing at 2,000 r.p.m. at a boost pressure of 20 inches of mercury.

Measurement of Gas Temperatures in an Internal Combustion Engine. (A. E. Hershey, Sci. Absts. (Section B), Vol. 39, No. 462, 29/6/36, p. 349 . A.S.M.E., Trans. 58, pp. 195-201, April, 1936.) (1900 Great Britain.)

A summary is given of the various methods used in determining gas temperatures in an internal combustion engine, with references to the various papers and reports published on the subject. Three general methods are briefly described, but the major part of the paper is devoted to a description of the experiments carried out at the University of Illinois. These form the basis of calculation of temperatures from radiation emission and absorption measurements, and include the measurement of temperatures by spectral line reversal; the latter is regarded as the only reliable method devised for this purpose. Sectional drawings of the apparatus are included and the results are given in the form of curves, a comparison being made with the calculated values of other workers, and possible reasons are given for discrepancies.

Further Studies of Flame Movement and Pressure Development in an Engine Cylinder. (C. F. Marvin, Jnr., N.A.C.A. Report No. 556, 1936.) (2055 U.S.A.)

The flame movement was traced by stroboscope examination of 30 small windows placed in the combustion head of an $L$ head engine. Various heads were tried, the average compression ratio being $5 / 1$, the bore and stroke of the engine was $3 \frac{3}{4}$ inches and 4 inches respectively, the speed of operation varying between 600 and 1,000 r.p.m. Motor benzol was used as fuel, the mixture generally being that giving maximum power. Of interest is the uniform spread of the flame, showing predominance of small scale turbulence and absence of pronounced swirl.

The photographs show that flame speed and rate of pressure rise increase nearly as fast as engine speed, i.e., complete inflammation keeps pace with position of maximum pressure as obtained from the indicator diagram.

The shortest combustion times and most rapid use of pressure are obtained by using multiple spark plugs.

Distribution of Heat Loss to the Jackets in an Internal Combustion Engine Cylinder. (C. F. Taylor, J. Aer. Sci., Vol. 3, No. 8, June, I936, pp. 282286.) (2058 U.S.A.)

Tests were carried out on a single cylinder water-cooled Liberty Az aero engine. 
Separate cooling was applied to the jacket, head and exhaust valve passage. 'The measurements included power output, fuel consumption, cooling water quantity and temperature and spark setting.

The effect of mixture strength, compression ratio, ignition advance and engine speed on the heat transmission was investigated.

The following represents an average distribution of heat loss:-

$\begin{array}{llllll}\text { Cylinder head } & \ldots & \ldots & \ldots & 5^{\circ} & \text { per cent. } \\ \text { Cylinder jacket } & \ldots & \ldots & \ldots & 3^{\circ} & , \\ \text { Exhaust valve passage } & \ldots & \text { 20 }\end{array}$

Ducted Radiators. (F. W. Meredith, Airc. Eng., Vol. 8, No. 9o, August, 1935, pp. 213-217.) (2338 Great Britain.)

In a freely exposed radiator, the induction efficiency is of the order of 0.5 . Considering the radiator as an actuator disc, the velocity through the disc is thus 0.6 of the velocity of the stream in which it is exposed. In the case of a ducted radiator, the induction efficiency (=duct efficiency) is generally above 0.9 . The power expended in drag is thus only about two-thirds of the power expended with the same radiator freely exposed at the speed at which it would provide the required cooling.

It is assumed in this investigation that there exists parallel flow at the duct exit and that the issuing stream does not disturb the flow of the external stream.

Provided exit conditions are adjusted to suit speed of aircraft, there is thus no need for an increase in cooling power with forward speed.

Further, the combined effect of compressibility and heat transfer may reduce this power consumption for cooling to zero, provided the radiator is of sufficient cross-section. If the engine exhaust heat is added near the duct exit, the combination may even result in a net gain in power, estimated at 5 per cent. for an aircraft speed of 300 m.p.h. (velocity through radiator 100 m.p.h.). Further experimental data on length and diameter of tubes in ducted radiators are required before this can be investigated further.

Survey of the Causes of Power Plant Failures-Air Line and Private Planes. (U.S. Bureau of Air Commerce Report.) (Inter Avia., No. 350, 3/8/36, pp. I-3.) $(2567$ U.S.A. $)$

The analysis classifies failures according to three major groups : Engine proper, engine installation and airscrew. The average percentages over the five-year period 1931-1935 are 6o, 30 and Io per cent. respectively.

There is a tendency for the percentage engine failure increasing, as installation and propeller become more reliable.

The most vulnerable point of the engine is the alloy head-next come exhaust valves and spark plugs (effect of leaded fuels).

Half the installation troubles are due to the fuel system.

Airscrew reduction gears are now almost faultless.

Ignition Process in Diesel Engines. (W. Wentzel, Forschung auf dem Gebiete des Ingenieurwesens, Vol. 6, No. 3, May-June, 1935. Translation N.A.C.A. Tech. Memo. No. 797, June, 1936.) (2633 Germany.)

The writer analyses the heating and vaporisation process of fuel droplets in a compression ignition engine on the basis of the theory of similitude and concludes that the required period for heating and complete vaporisation of the average size fuel drop is only a fraction of the actually observed ignition lag. The result is that ignition takes place in the fuel vapour-air mixture rather than on the surface of the drop. The theoretical result is in accord with the experimental observations by Rothrock and Waldron (see Abstract No. 39/62). The combustion shock occurring at lower terminal compression temperature, especially in the combustion of coal tar oil, is attributed to the simultaneous ignition of a larger fuel vapour volume formed prior to ignition. 
Blower Cooling of Radial Engines (based on N.A.C.A. Tech. Note No. 572). (Autom. Ind., Vol. 75, No. 9, 29/8/36, pp. 28I and 29I.) (2716 U.S.A.)

From the results of these tests the following conclusions were drawn:-

(I) The minimum power required for satisfactory cooling with an over-all blower efficiency of roo per cent. varied from 2 to 6 per cent. of the engine power depending on the operating conditions.

(2) The shape of the jacket had a large effect on the cylinder temperatures. Increasing the air speed over the front of the cylinder by keeping the greater part of the circumference of the cylinder covered by the jacket reduced the temperatures over the entire cylinder.

(3) The temperature difference between the cylinder and the cooling air varied inversely as the 0.4 to 0.6 power of the cooling air weight, depending on the location of the thermo-couple; those on the barrel varied as the higher power of the air flow.

(4) The total head drop across the cylinder varied as the 1.77-2.04 power of the cooling-air weight, depending on the cylinder and jacket combination. The power required for cooling varied as the 2.8I power of the cooling-air weight for three of the cylinder and jacket combinations and as the 2.90 power for the fourth combination.

(5) An air quantity of $\mathrm{r} .0 \mathrm{glb}$. per sec., properly directed and kept in contact with the cylinder, would satisfactorily cool the Wasp $\mathrm{H}$ cylinder, when it was developing 45 b.h.p., maximum temperature being $475^{\circ} \mathrm{F}$.

Effect of Nozzle Design on Fuel Spray and Flame Formation in a High-Speed Compression-Ignition Engine. (A. M. Rothrock and C. D. Waldron, N.A.C.A. Report No. 561 , 1936.) (2798 U.S.A.)

Fuel was injected from different types of injection nozzles into the combustion chamber of the N.A.C.A. combustion apparatus, operated as a compression ignition engine; high speed motion pictures were taken at the rate of 2,200 frames per second of the fuel sprays and the combustion.

The photographs indicate that the rate of vapour diffusion from the spray is comparatively slow and that this slow rate of diffusion for combustion chambers with little or no air flow prevents the compression ignition engine, with the present methods of fuel injection, from giving the high performance inherent in the compression ratios. It is concluded that high performance cannot be realised until the methods of distributing the fuel are improved by means of the injection nozzle design, air flow, or both (see also Abstract No. 39/60).

\section{Exhaust Gas Analysis During Flight. (Les Ailes, No. 791, 24/9/36, pp. 5-6.) (2864 France.)}

The well known Dorsat apparatus has been simplified by using vessels made of rubber for the reagents. In this way the gas can be introduced by mere hand pressure and the troublesome adjustable reservoir is avoided.

The apparatus is contained in a metal frame suspended on rubber cords. It is stated that flight tests have shown that the mixture strength is generally too rich and that economies up to 30 per cent. in fuel consumption should be possible without affecting engine temperature detrimentally.

\section{German Progress in Oil-Driven Aircraft. (Les Ailes, No. 79г, 24/9/36, p. 3.) (2865 Germany.)}

During 1935 at least ten German transport machines, fitted with oil engines, carried out regular flights, covering over one million miles between them. It is reckoned that this year the mileage will be at least doubled.

The Junkers firm are said to produce 200 engines a month, and according to the French author ro per cent. of the German heavy bombers are fitted with Diesel engines. 
The Junkers firm are producing a new engine rated at 1,200 b.h.p. Eight of these engines driving four propellers are destined for the new DO 20 flying boat under construction.

\section{Experiments on the Friction and Leakage of Piston Rings. (M. Eweis,} Forschungsheft, No. 37I, March-April, 1935.) (2895 Germany.)

The author obtains an expression for the friction force of a piston ring, using the fundamental equation of laminar viscous flow and assuming that the variation in thickness of the oil film is limited to a small region in the neighbourhood of the rounded edge of the ring.

He next investigates the question of leakage, on the assumption that the ring never leaves the seat furthest away from the piston crown. (This assumption appears justified for the experimental condition subsequently employed, in which the ring inertia is unable to overcome the combined effect of gas pressure and friction.)

The theoretical figures for leakage and friction were subsequently tested by an experimental ring in which the piston and rings are stationary whilst the cylinder wall is reciprocated. The top ring is subjected to a variable gas pressure supplied by a compressor, the pressure variation at this ring as well as the gas pressure behind the other rings being recorded by a Farnborough electrical indicator. The frictional force on the piston is recorded piezo-electrically.

It appears that the variation in gas pressure behind the rings followed theory, and is rapidly damped out as the number of rings increase. The conditions of experiment were such that a proper oil film was not generally established between ring and cylinder (piston speed insufficient).

The friction was thus mainly of the boundary type and increased linearly with gas load, whilst diminishing with increase of speed.

From the theoretical investigation detailed in the beginning of the report (fluid friction), the friction should increase as $v^{\frac{1}{2}} / p^{\frac{\pi}{3}}$, when $v=$ piston speed and $p=f$ (gas pressure).

Defence of Heavy Bombers Against Enemy Aircraft. (K. L. Wassiliew, Luftwehr, Vol. 3, No. 3, March, 1936, pp. I 18-1 22.) (I384 Germany.)

The article deals primarily with the preparation for and execution of long distance bombing raids.

Preparation.- In order to safeguard machines as far as possible from enemy attack, whilst still on the ground, the bombers should be distributed over a wide area and only concentrated into groups near the frontier when ready to undertake the raid.

To render this concentration reasonably safe, effective reconnaissance is essential.

Direct protection to the assembled bombers may be afforded by fighting squadrons stationed along probable lines of enemy approach, or a diversion may be created by light bombing raids. If, in spite of all, the enemy approaches too closely to the point of intended concentration the heavy bombers must be disbanded towards the rear. To ensure such mobility is the object of peace time training.

ExECUTION.-Heavy bombers should only be used against targets of importance.

The necessary defence ties down large enemy forces and decisive actions may result.

Air engagements resemble fleet action in so far as finality should be the principal aim and it is, therefore, useless to carry, out attacks of this kind without ample reserves.

For mutual assistance, bombers should operate in groups. A certain percentage of each group (up to 33 per cent.), instead of carrying bombs, are provided with armour and heavy guns. These are placed on the outside of the formation to supplement the machine gun fire of the bombers proper. 
When crossing the frontier and till the vicinity of the objective is reached, groups should not exceed $I_{5}$ individual machines. This gives sufficient mutual protection without sacrificing mobility and betraying objective. In order to concentrate bombing damage $2-3$ of such groups combine in an attack, but split up after release of bombs. Fresh groups carry on as they arrive, the engagement being continuous as long as reserves last.

Co-operation of Anti-Aircraft Artillery and Fighting Aircraft in Defence Against Bombers. (C. L. Chenault, from Coast Artillery Journal, Nov.-Dec., 1935. Luftwehr, Vol. 3, No. 3, March, 1936, pp. 127-131.) (1385 U.S.A.)

Co-operation between anti-aircraft artillery and aircraft is only possible at night if sufficient illumination is provided by means of searchlights.

During the late war efficient co-operation of these types was only provided in 1918 (I51 squadrons at Abbeville).

Reference is made to some recent experiments in U.S.A. (Maxwell Field, I934). In these the bomber operated at relatively low altitudes ( $12, \infty 00$ feet). It was found that the various units co-operating in the defence (such as alarm post, sound ranging, battery and fighters) could be controlled by a single authority.

Interception of the bomber can apparently be assured if not less than 40 miles of territory has to be flown over by the bomber before it can attack its objective.

This territory has to be provided with a sufficient number of searchlights ( ${ }_{5}$ on a front of 50 miles).

If general protection has to be provided, defence is very much more expensive than attack. Usually the line of approach of the enemy can, however, be predicted before he sets off and this simplifies the problem.

If the attack is carried out at great altitudes the bombing searchlights can no longer co-operate.

In forcing the enemy to fly high, searchlight will, however, achieve some useful purpose, besides helping to identify friend from foe should the fighting continue to lower altitudes.

Defence of Aerodromes Against Air Attack. (Poplawski, from W.P.O. (U.S.S.R.), Dec., 1935. Luftwehr, Vol. 3, No. 3, March, I936, p. I33.) (2198 U.S.S.R.)

The danger of enemy attack is greatest when own aircraft are either getting ready to take-off or have just landed.

The enemy presumably will attack at low altitude so as to reduce danger from anti-aircraft batteries.

The defence measures consist of :-

I. Warning of raid.

The aerodrome must be linked up with the general system and if possible have its own warning organisation.

Own aircraft may only approach aerodrome at fixed heights and in a given direction. Possible provision of balloon curtain and artificial fog.

2. Provision of sufficient machine guns on the ground. Own aircraft should be parked so that its machine guns are available.

Ground personnel supplied with quick-firing rifles.

3. Distribution of fuel and munition stores into small units.

4. Underground shelters.

5. Ground organisation to deal with clearing debris after raid.

6. Training of personnel and especially determining responsibility of various heads (officers in charge of flight, station, batteries, signals). 
The Use of Captive Balloons in Aerial Defence. (J. Lucas, Rev. de l'Arm. de l'Air, No. 85, Aug., I936, pp. 863-867.) (2881 France.)

Various types of net defences used by the German, French, English and Italian Governments in the last war are described.

Two instances where German machines were caught in the nets are described.

The presence of 120 balloons on the outskirts of Paris is held to have forced German raiders to alter line of approach, whilst the immunity of Venice from Austrian air attack is considered to be due to the very efficient Italian balloon defence. The expense of such a scheme is held to be commensurable with the value of the targets.

Balloon curtains can be operated by a relatively small staff requiring no expensive instruments or training and the method compares favourably with antiaircraft gunnery.

Modern developments have raised the possible ceiling of balloon curtains from $4,000 \mathrm{~m}$. (highest Italian) to $7,000 \mathrm{~m}$. The mere suspected presence of such curtains has a valuable psychological effect.

French Military Aircraft. (Aero Digest, Vol. 29, No. 2, Aug., 1936, pp. 34-36 and $5^{8}$, and No. 3, Sept., 1936, pp. 28-31.) (2752/2420 U.S.A.)

A brief review of the present position.

Part I deals with fighters (single and two-seat) and light bombers (multi-seat).

Part II considers heavy bombers, reconnaissance and seaplanes, as well as $z$

list of civil aircraft readily convertible for military use.

The article is copiously illustrated.

The following are estimated numbers:-

\begin{tabular}{|c|c|c|c|c|}
\hline Fighters & $\ldots$ & $\ldots$ & $\ldots$ & 1,400 \\
\hline Bombers $\quad \ldots$ & $\ldots$ & $\cdots$ & & 900 \\
\hline Reconnaissance & $\ldots$ & $\ldots$ & & 60 \\
\hline Seaplanes ... & $\ldots$ & $\ldots$ & $\ldots$ & 600 \\
\hline
\end{tabular}

Over a third of these are stated to be obsolete.

Prices of American Fighting Aircraft. (Luftwissen, Vol. 3, No. 8, August, 1936, p. 2 r.) (2899 U.S.A.)

The following tenders were received by the U.S.A. Government for the supply of a modern single-seater fighter to Air Corps specification :-

\begin{tabular}{|c|c|c|c|}
\hline No. in Series & \multicolumn{2}{|c|}{ Price per Aircraft } & Firm \\
\hline 25 & 29,412 & ollars. & \\
\hline 200 & I $4,5^{\circ}$ & ," & \\
\hline 25 & 34,148 & ", & Chance Vought. \\
\hline $\begin{array}{r}200 \\
25\end{array}$ & $\begin{array}{l}10,05^{1} \\
44, \infty 00\end{array}$ & ,", & Concolidated Aircraft \\
\hline 200 & 24,260 & ," & \\
\hline
\end{tabular}

Technical Production of Acetylene. (H. P. A. Groll and J. Burgin (Shell Development Co.), Can. 353,604 , Oct. ${ }_{5}$. Chem. Absts., Vol. 30 , No. 5, ro $/ 3 / 3^{6}$, p. I 543.) (104I U.S.A.)

A gaseous mixture of a hydrocarbon and oxygen is subjected to incomplete combustion in an enclosed apparatus at a linear gas velocity not greater than the flame velocity of the mixture. The linear gas velocity is subsequently increased to exceed the flame velocity throughout at least the greater part of the flame, while combustion is maintained by part of the flame proper.

Liquid Fuels for Diesel Engines. (British Patent No. 432,592. Chem. Absts., Vol. 3o, No. 2, 20/1/36, p. 597.) (I043 U.S.A.)

The fuel consists primarily of a hydrocarbon to which o.I to 5 per cent. of true esters (other than lactide or lactone) are added. 
These esters must have a boiling point above ${ }_{5} 0^{\circ} \mathrm{C}$. and a suitable example is the hexyl ester obtained from the oxidation of wax.

Mechanism of the Oxidation of Petroleum Hydrocarbons. (A. K. Plisov, Chem. Absts., Vol. 3o, No. I I, 10/6/36, p. 3975.) (I793 U.S.A.)

Air was passed through $100 \mathrm{gm}$. of the hydrocarbon at the rate of 200 litres/hour, the temperature being $120^{\circ}$ and $15^{\circ} \mathrm{C}$. respectively, both with and without catalysts. In the former case, the quantity of peroxide formed diminished progressively with time and none could be detected after four hours. In the absence of catalysts, the peroxide content at first increases to a maximum and subsequently decreases to a lower constant value. The amount of acid formed, on the other hand, is unaffected by the catalysts and increases continuously with time of experiments.

Production of Acetylene from Petroleum according to the Method of the Firm "l'Air Liquid." (S. Ya. Miloslavski and D. L. Glizmanenko, Chem. Absts., Vol. 30, No. I I, 10/6/36, p. 3976.) (1794 U.S.A.)

Solar oil is cracked by an electric arc producing a gas rich in acetylene (35 per cent.).

The energy consumption is approximately $3.5 \mathrm{kw}$. hours per cubic metre of gas

Rating Aviation Fuels in Full-Scale Aircraft Engines. (C. B. Veal, Chem. Absts., Vol. 3o, No. i i, ro/6/36, p. 3988.) (I795 U.S.A.)

The relative order of merit of aircraft fuels depends on the severity of the conditions and the design of the engines. The present C.F.R. method for rating fuels will be retained for the present in want of anything better.

Use of Inhibitors in Gasoline. (C. D. Lowry, Jnr., Chem. Absts., Vol. 3o, No. I I, 10/6/36, p. 3989.) (I796 U.S.A.)

The inhibitory value of certain substances such as phenol and amines, depends on the critical oxidation potential. Accelerated oxidation tests are a useful but by no means infallible guide as to the stability of fuels under commercial conditions.

Nature of the Octane Scale. (E. B. Evans and others, Chem. Absts., Vol. 30, No. I I, Io/6/36, p. 3991.) (I 797 U.S.A.)

As an alternative to the octane scale of rating fuels, a pressure scale is proposed. This is based on the limiting compression pressure above which knocking takes place. The new scale was satisfactorily extended to deal with fuels beyond the 100 octane scale.

Alteration of Lubricating Oils in Use and Their Regeneration. (H. Karaptner, Chem. Absts., Vol. 30, No. II, Io/6/36, p. 3994.) (I798 U.S.A.)

Fresh oil, used oil, filtered oil and regenerated oil were compared. Regeneration yields a product very similar to the original oil.

Eighty-five references.

Improved Lubricants and Lubrication. 1. Fundamental Chemical and Physical Forces in Lubrication. (G. L. Clark and others, Chem. Absts., Vol. $3^{\circ}$, No. I I, 10/6/36, p. 3995.) (I799 U.S.A.)

$\mathrm{X}$-ray investigation of adsorbed film of chlorinated esters of the fatty acids shows that the thickness of the orientated film may be comparable to that existing in bearings with viscous lubrication. Such orientated films are not readily disorganised by temperature rises and thus afford better protection against wear. 
Testing Liquid Lubricants. (U.S. Patent No. 2,037,365. L. Cammen, Chem. Absts., Vol. 30, No. 1I, 10/6/36, p. 4002.) (I 801 U.S.A.)

The adsorption of the oil is measured by noting the loss of weight occurring as a disc wetted with the oil is gradually speeded up.

Motor Fuels. (E. V. Bereslavsky, Chem. and Ind., Vol. 55, No. 27, 3/7/36, p. 584. B.P. 444,026, I I/9/34; U.S., 24/1/34.) (1903 Great Britain.)

The fuel comprises a mixture of petrol ( 85 per cent.), anhyd Et $\mathrm{OH}$ (1o per cent.), and a sec. or tert. hydroaromatic alcohol, e.g., terpineol, and/or an open chain unsaturated alcohol, e.g., geraniol (5 per cent.). Steam-distilled pine oil, preferably treated with a gum inhibitor, may be used as the third constituent. It functions as a blending agent and also increases the calorific value and the anti-knock value of the mixed fuel.

Electron Diffraction Analysis of the Orientation of the Molecules of Lubricating Oils. (L. T. Andrew, Chem. Absts., Vol. 30, No. I 2, 20/6/36, p. 4307 . Trans. Faraday Soc. 32, 607-16, 1936.) (I914 U.S.A.)

The best boundary lubricants are those with maximum orientation and with jittle or no tendency to oxidise. The orientation test indicates the following arrangement of the oils tested in the order of diminishing quality : (I) Mineral oil with small percentage of fatty oil; (2) Russian, California and non-viscous Pennsylvania; and (3) Texas oil, poor owing to gumming.

There is no relation between viscosity and orientation.

Experiments on heating polished metal surfaces in oil at $250^{\circ} \mathrm{C}$. indicate that metal corrosion by oil is due to an accumulation of an amorphous layer, probably of organic material.

The Explosion of Methane (Fire Damp) by the Filament of Electric Incandescent Lamps. (E. Cotté, Comp. Rend., Vol. 201, No. 27, 3\%/12/35, pp. I $484^{-}$ 1485.) (I939 France.)

Experiments were carried out using a 20 per cent. coal gas/air mixture. On puncturing the glass bulb with a file, explosions were obtained inside the bulb. These were not propagated to the outside, until the hole in the glass exceeded a certain minimum diameter $(2 \mathrm{~mm}$.). As the hole is further increased, the explosions (after passing through a maximum) become less certain and none is formed if the glass is removed entirely.

The flash produced by the burning of the filament (4-volt) will not ignite the gaseous mixture. Electric lamps in mines should therefore have bulbs of large diameter made of a brittle glass which collapses completely under shock.

Researches on Increasing the Sensitivity of Aviation Petrols to Lead Tetra Ethyl. (A. Feigin and V. V. Zeleniak, Aeron. Eng. (U.S.S.R.), No. 6, June, I936, pp. 41-45. Available as Translation No. 334.) (1955 U.S.S.R.)

The experiments were carried out on the following six fuels (octane determination C.F.R., 900 r.p.m., mixture temperature $150^{\circ} \mathrm{C}$.).

\begin{tabular}{|c|c|c|c|c|c|c|c|c|c|}
\hline & & & & & Dis & illation & & & Octane \\
\hline & Name & & Density & Ist drop & I0 $\%$ & ${ }^{\circ} \mathrm{C} .^{50 \%}$ & $90 \%$ & End part & No. \\
\hline Baku & Standard & Aviation & 0.749 & $7^{8}$ & 90 & 107 & I 37 & 165 & 69 \\
\hline Baku & No. I & $\ldots \quad \ldots$ & 0.745 & 77 & 89 & IOI & 119 & I 49 & 74.5 \\
\hline Baku & No. 2 & $\ldots$ & $0.7^{2} 5$ & $5^{\circ}$ & 70 & 84 & 100 & 130 & 78 \\
\hline Grozn & ly No. I & $\ldots$ & 0.668 & 27 & $3^{6}$ & 68 & 149 & 165 & 69 \\
\hline Grozn & y No. 2 & $\ldots$ & $0.67 \mathrm{I}$ & 27 & 35 & 73 & 152 & 167 & 66 \\
\hline Grozn & y No. 3 & $\ldots$ & - & & Dis & ils un & $40^{\circ} \mathrm{C}$ & & 80 \\
\hline
\end{tabular}


The following table gives the lead response of some patent fuels and mixtures :-

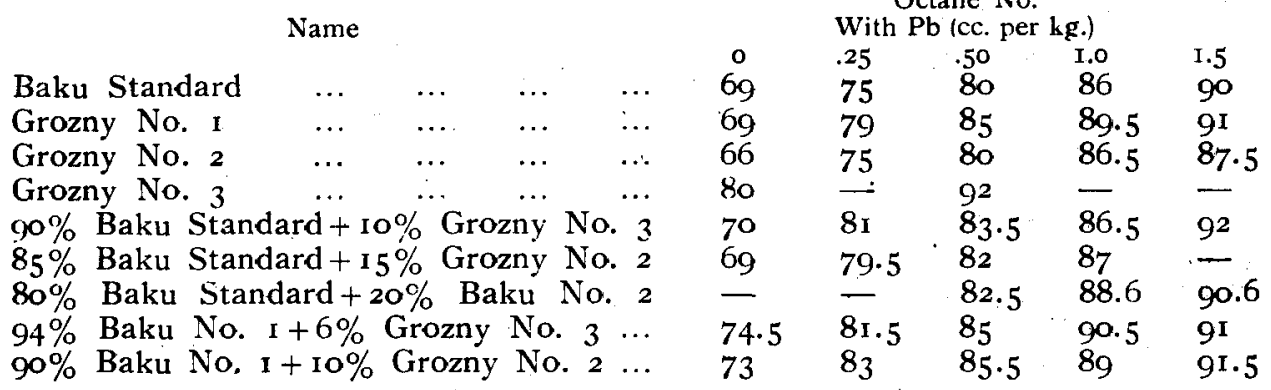

\section{Distillation Characteristios of Mixtures.}

Name

Distillation ${ }^{\circ} \mathrm{C}$.

\begin{tabular}{|c|c|c|c|c|c|c|c|c|c|c|c|}
\hline & & Name & & & & drop & 10 $\%$ & $50 \%$ & $90 \%$ & 10 & Density \\
\hline & Baku & dard $+10 \%$ & Grozny & No. & 3 & $45^{\circ}$ & $74^{\circ}$ & $108^{\circ}$ & $139^{\circ}$ & $170^{\circ}$ & \\
\hline 7 & Baku & Standard + I $5 \%$ & Grozny & No. & 2 & $60^{\circ}$ & $77^{\circ}$ & $105^{\circ}$ & $13^{\circ}$ & $164^{\circ}$ & 0.73 \\
\hline 7 & Baku & Standard ... & $\cdots$ & & $\cdots$ & $5^{1^{\circ}}$ & $7^{8^{\circ}}$ & $102^{\circ}$ & $136^{\circ}$ & $168^{\circ}$ & 0.74 \\
\hline .7 & Baku & o. $1+6 \%$ Gro & zny No. & 3 & & $46^{\circ}$ & $75^{\circ}$ & $102^{\circ}$ & $122^{\circ}$ & $140^{\circ}$ & $0.73^{1}$ \\
\hline & aku & No. $1+10 \%$ & zny & & & $62^{\circ}$ & $80^{\circ}$ & $100^{\circ}$ & $136^{\circ}$ & I $47^{\circ}$ & 0.7 \\
\hline
\end{tabular}

From the above the following conclusions are drawn:-

(I) The high lead response of the Grozny petrols (for small addition of $\mathrm{Pb}$ ).

(2) The improvement in the lead response of Baku standard by the addition of Grozny (for small additions of $\mathrm{Pb}$ ).

(3) The improvement of Baku I over the Standard Baku.

(4) The cost of the additional equipment required to produce these low boiling petrols is insignificant compared with the economy and other advantages gained by reducing the amount of lead required.

In the case of Octane No. 85 , this reduction amounts to 50 per cent., the original Baku Standard requiring I cc. $/ \mathrm{kg}$. against $0.5 \mathrm{cc}$. for Baku No. I/Grozny mixtures (see also Abstract No. 39/86).

N.B.-I cc. of $\mathrm{Pb} / \mathrm{kg}$. corresponds approximately to $3.5 \mathrm{cc} / \mathrm{gallon}$.

Treatment of Motor Fuels. (P. Poetschke, Chem. and Ind., Vol. 55, No. 29, I7/7/36, p. 630. U.S. Patent No. 2,0.18,570.) (1995 Great Britain.)

Anti-knock cartridges are made of a mixture of $\mathrm{C}_{10} \mathrm{H}_{8}$ and stearic acid (I), with or without a metal container, the interior being filled with a solid mixture of $\mathrm{Pb} \mathrm{Et}_{4}$ and ( $\left.\mathrm{l}\right)$. These cartridges are dissolved in the fuel as required.

Gasolines and Gasoline Fractions. Susceptibility to Tetra Ethyl Lead and Aniline. (C. O. Tongberg and others, Ind. and Eng. Chem. (Indust. Edn.), Vol. 28, No. 7, July, 1936, p. 792-794.) (2032 U.S.A.)

The lead response of different fractions of a petrol as measured in a series $30 B$ ethyl knock-rating engine differ considerably. These differences are thought to be due to the presence of certain catalyst poisons such as sulphur compounds.

The increase in octane number due to the addition of aniline is practically linear for additions between 2 and 7 per cent.

When aniline and lead are used together, the results are additive.

Absorption of Air by Mineral Oils. (A. Gemant, Chem. Absts., Vol. 30, No. I3, 10/7/36, p. $465^{6 .)}$ (2087 U.S.A.)

The Bunsen coefficient for a series of oils varied from 0.073 to 0.106 , decreasing with increase in oil viscosity. The absorption coefficient is practically indepen- 
dent of temperatures between the limits of $15^{\circ} \mathrm{C}$. and $80^{\circ} \mathrm{C}$. This throws doubt on the theory that breakdown strength of oil varies proportionally to the air content of the oil.

Heat Conductivity and Specific Heat of Oils. (C. Lochmann, Chem. Absts., Vol. $3^{\circ}$, No. $13,10 / 7 / 3^{6}$, p. 4656.) (2088 U.S.A.)

$K=$ conductivity and $C=$ specific heat.

Values given in the literature are summarised for liquid petroleum products $K$ in $\left(\mathrm{gm} . \mathrm{cal} . / \mathrm{sec} . / \mathrm{cm} .{ }^{2} /{ }^{\circ} \mathrm{C} . / \mathrm{cm}.\right)=0.0002804 \times(\mathrm{I}-0.00054 t) / d$ and $C$ in (gm. cal. $/ \mathrm{gm}.)=(0.4024+0.0008 \mathrm{I} t) d^{\frac{1}{2}}$

when $d=$ density at $15^{\circ} \mathrm{C}$.

$t=$ temperature ${ }^{\circ} \mathrm{C}$.

The experimental results disprove the theory that petroleum asphalt is a supercooled liquid producing a latent heat exchange on solidification.

Anti-Knock Fuels. (Chem. Absts., Vol. 30, No. I3, Io/7/36, p. 4662. French Patent No. 793,967, 1936.) (2089 U.S.A.)

The use of mixtures of carboxylated fatty acids and amino compounds of all structures is claimed as an anti-knock agent. A mixture of $\mathrm{Ph} \mathrm{NH}_{2}$ and stearic acid or soaps of ethanolamines is also efficacious.

Lubricants. (Chem. Absts., Vol. 30, No. I3, 10/7/36, p. 4663. French Patent No. 793,602.) (2090 U.S.A.)

Lubricants suitable for high pressures and temperatures are made by suspending, in a mineral oil, non-corrosive particles acting as cushions. Such particles of larger than colloidal dimensions are :-

(I) Polymerised drying oils (including caster).

(2) Vulcanised organic substances (rubber).

(3) Insoluble hydrocarbon products (asphalt).

(4) Insoluble soaps (Al soap of oxidised aleurite oils).

Penetrating Oil Suitable for Loosening Rusted Connections. (B. H. Lincoln and A. Henriksen, Chem. Absts., Vol. 30, No. 13, ro/7/36, p. 4664 . U.S.A. Patent No. 2,041,076.) (209I U.S.A.)

Three per cent. of chlorinated stearic acid is added to a low boiling petroleum, butyl butyrate acting as solvent. Other examples are given.

Modern Tests on Fuels for High-Speed Diesel Engines. (A. Hagemann and T. Hammerich, Chem. and Ind., Vol. 55, No. 35, $28 / 8 / 36$, p. 775.$) \quad(2546$ Great Britain.)

The "filtration index" at any desired temperature is obtained by comparing the time of flow of the oil through a $0.1 \mathrm{~mm}$. mesh gauze in a special apparatus with the time of flow through the same apparatus without the gauze. The corrosion of $\mathrm{Cu}$ and $\mathrm{Zn}$ is examined by immersing strips of these metals in the oil at $50^{\circ}$. The tendency to form coke is shown by determining the hard asphalt and insoluble residue formed on heating the oil at $150^{\circ}$ for $2 \mathrm{hr}$. in a stainless steel bomb with air at 20 atm. The conditions for determining knock-rating (cetene number) on the army Diesel test engine are briefly outlined. (See also Abstract No. 39/1 18.)

Distillation Curves of Lubricating Oils. (C. Walther, Chem. and Ind., Vol. 55, No. $35,28 / 8 / 36$, pp. 775-776.) (2547 Great Britain.)

It is considered that a pressure of $40 \mathrm{~mm}$. $\mathrm{Hg}$ (as specified by the U.S. Bureau of Mines) is too high for distilling lubricating oil fractions. A laboratory apparatus is described which enables the distillation curve to be obtained under 
a pressure of Io $\mathrm{mm}$. B.p. at one pressure are converted into b.p. at other pressures by means of the Beale-Docksey diagram.

Viscosities of Lubricating Oils at Low Temperatures. (Y. Tanaka and others, Chem. and Ind., Vol. 55, No. 35, 28/8/36, p. 776.) (2548 Great Britain.)

The viscosity of numerous lubricating oils at temperatures down to $-35^{\circ}$ agree fairly well with the empirical formula $\varepsilon=e^{c}(T-b)^{n}$, where $c, b$ and $n$ are constants and $\epsilon$ is the ratio between the viscosity at $T$ and at $3^{\circ} 3^{\circ}$ absolute.

Relation Between the Properties of Lubricating Oil and its Chemical Structure. (H. I. Waterman and J. J. Leendertse, Chem. and Ind., Vol. 55, No. 35, 28/8/36, p. 776 .) (2549 Great Britain.)

The composition of a lubricating oil, e.g., the proportion of aromatic and naphthene rings and paraffinic side chains, can be approximately deduced from determinations of mol. wt., $n, d$ and $\mathrm{NH}_{2}$ Ph point, making use of the molecular refraction. Correlation of the chemical nature of lubricating oils and their behaviour in practice may give useful results.

Laboratory Method for Determination of the Vaporisability of Lubricating Oils for Internal-Combustion Engines. (K. Noack, Chem. and Ind., Vol. 55, No. $35,28 / 8 / 3^{6}$, p. $77^{6}$.) (2550 Great Britain.)

Sixty-five $g$. of oil are electrically heated for I hr. at $250^{\circ}$ under a pressure of $20 \mathrm{~mm} . \mathrm{H}_{2} \mathrm{O}$ in a weighed metal crucible and the loss in weight is determined. Duplication to \pm 0.5 per cent. is claimed.

Production of Non-Knocking Motor Fuels. (J. Y. Johnson, Chem. and Ind, Vol. 55, No. $35,28 / 8 / 36$, p. $77^{8}$.) (2551 Great Britain.)

A mixture of alcohols, mainly butyl and higher alcohols, is obtained by heating $\mathrm{CO}$ and $\mathrm{H}_{2}$ at $>5^{\circ} \mathrm{atm}$. in presence of a catalyst, e.g., $\mathrm{Zn} \mathrm{O}, \mathrm{Cr}_{2} \mathrm{O}_{3} \mathrm{Me} \mathrm{OH}$ is separated and the residual alcohols are dehydrated at $300^{\circ}$ by catalysts, e.g., $\mathrm{Al}_{2} \mathrm{O}_{3}$ iso Olefines are thus obtained which are partly polymerised to di- and tri-merides by $\mathrm{H}_{2} \mathrm{SO}_{4}$. The product is mixed with monomeric higher isoalcohols (in some cases after hydrogenation of the latter) to give a motor fuel of high anti-knock value.

Fuels for Use in Internal-Combustion Engines and for Other Purposes. (R. G. Terakopoff, Chem. and Ind., Vol. 55, No. 35, 28/8/36, p. $\left.77^{8 .}\right)\left(255^{2}\right.$ Great Britain.)

A mixture of paraldehyde $(20-50$ pts. by vol.) and a polycyclic hydrocarbon (50-80), e.g., tetrahydronaphthalene, with or without a thin lubricating oil as upper cylinder lubricant, is added to liquid fuels for internal combustion engines in order to assist in initiating or promoting combustion of the fuel.

An aromatic amine, e.g., $\mathrm{NH}_{2} \mathrm{PH}, \mathrm{NHPhMe}$, or preferably aminocymene, may also be present. Normally 0.5 per cent. of the dope is added to gasoline and I per cent. to Diesel fuels.

Motor Fuel. (A. C. G. Egerton, Chem. Absts., Vol. 30, No. I5, Io/8/36, p. 5396.) (2559 U.S.A.)

Diesel or other engine fuel is doped with a peroxide in which one of the peroxide $O$ atoms is attached to an alkyl or aliphatic acyl radical while the other is attached to $\mathrm{H}$ or to a sec. alkyl or aliphatic acyl radical. Thus $\mathrm{I}-2$ per cent. of diethyl peroxide is added to petroleum fuel oil, coal oil or creosote. 
Relation Between the. Constitution and Viscosity Characteristics of Hydrocarbons. (W. R. Wiggins, Chem. Absts., Vol. 30, No. r 5, 1o/8/36, p. 5400.) (2560 U.S.A.)

Since the change in viscosity with change in temperature depends upon the viscosity, the fractional viscosity temperature coefficient, $1 / n . \Delta n / t$, was proposed.

This was evaluated for 16 hydrocarbons of high mol. wt. by dividing the average change in viscosity per degree in intervals of $20^{\circ}$ by the viscosity at the mid-point of the temperature range. The fractional temperature coefficient $=(n 20-n 40) / 20 \times n$ 30. . When these values were plotted against log. $n$, giving straight lines, the graph for aliphatic hydrocarbons was steepest, that for alkylated monocyclic hydrocarbons next, and that for polycyclic least. The expression

$$
\Delta v / \Delta t . \mathrm{x} / v \log . v
$$

for viscosities in kinematic units was evaluated for three Pennsylvania and three Gulf Coast oils. The results were lower for the Pennsylvania oils throughout.

The expression differs from the viscosity index of Dean and Davis (C.A. 24, 7I6) in that it is not based on any arbitrarily chosen series of oils. The study included observations upon the influence upon the viscosity of branching chains, unsatn., cyclic structure, mol. wt. and mol. vol., polycyclic structures, etc.

Fatty Oils as Lubricants for Motors. (J. Hübscher, Chem. Absts., Vol. 30, No. ${ }_{5} 5,10 / 8 / 3^{6}$, p. 540r.) (2562 U.S.A.)

Olive oil, refined so as to remove free acids, proteins, and mucilage, can be used as a lubricant for automobile engines. Its stability and the relatively slight change in viscosity with varying temperature compares favourably with mineral oil.

Testing of Lubricants. (H. J. Grough and W. J. Clenshaw, Chem. Absts., Vol. 3o, No. I5, 10/8/36, p. 5401.) (2563 U.S.A.)

Methods in use at the National Physical Laboratory are described.

A combination of bearing tests and engine tests has been evolved which is claimed to be of use in grading lubricants intended for motor car lubrication.

The Attack of Fuels on Various Materials. (K. R. Deitrich and W. Lohrengel, Chem. Absts., Vol. 30, No. I6, 2o/8/36, p. 5757.) (2650 U.S.A.)

A series of 19 metals and alloys has been subjected to the action of an alc. mixture (95 parts abs. Et $\mathrm{OH},{ }_{5}$ parts $\mathrm{Me} \mathrm{OH}$ ) and a benzine-alc: blend (1o per cent. of the alc. mixture) for ten weeks. Results of weekly detns. of metal weight changes are plotted showing the relative superiority of alloys over plain, galvanised and lead-covered iron.

Progress Report for 1935 on Lubricating Agents. (A. van der Wertl, Chem. Absts., Vol. 30, No. 16, 28/8/36, p. 5774.) (2651 U.S.A.)

U.S.A., British, German and French patents are listed with brief descriptions.

Relation Between the Standard Tests and the Quality of Lubricating Oils. (E. Thomas, Chem. Absts., Vol. 30, No. 6, 20/8/36, p. 5774.) (2652 U.S.A.)

A discussion of the practical significance of the viscosity index (Dean and Davis, C.A. 24, 7I6-7I7) and gravity index (McCluer and Fenske, C.A. 27, 834). The old idea that, of two oils having the same viscosity at the same temperature, the better is the one having the lower $d$, is confirmed by the calculation of the gravity index. 
Oiliness Index as a Criterion of Lubricating Oil Quality. (F. W. Breth and L. Liberthson, Chem. Absts., Vol. 30, No. 16, 20/8/36, p. 5775.) (2654 U.S.A.)

The Sperry Adher-O-Scope uses a thin metal band to which an oil film is applied, revolving at high speed for a definitc time in a conditional atmosphere, and constant temperature governed by the viscosity of the oil. The actual amount of oil adhering to the band is found to be an accurate and reproducible indication of the degree of oiliness.

The Laboratory Engine Testing of Motor Lubricants. (M. Fairlie, Gas and Oi! Journal, Vol. 34, No. 44, 19/3/36, pp. II 4 , I 77 and I19.) (2694 U.S.A.)

Experiments are carried out on a Waukesha type $2 \mathrm{~A}$ four-cylinder unit. By means of a rapid ethylene glycol circulator, cylinder temperature is kept at $250^{\circ} \mathrm{F}$. and crankcase at $220^{\circ} \mathrm{F}$. Or $320^{\circ} \mathrm{F}$. The engine is run for 50 hours at $1, \infty 0$ r.p.m., oil samples (roo cc.) being taken at intervals of $16,3^{2}$ and 50 hours.

The engine is started with one gallon of oil in the crankcase and replenishments are made after 16 and 32 hours. The drawn samples are investigated for:-

(1) Viscosity.

(2) Acidity

(3) Conradson carbon.

(4) Tar content.

(5) Induction period (this is number of hours required in Sinclair apparatus to reach I per cent. tar content).

During the test, the oil temperatures (pump discharge and sump) are noted, together with the flow of cooling medium required to maintain steady jacket temperature. A check is also kept on power and blow by temperature (crankcase breather).

With experience, the point at which ring sticking sets in can be approximately determined from a tendency' for cylinder temperature to rise, blow by temperature to increase and power to fall.

Ring sticking tendency and tar content of final sample increase together, but not proportionally. This shows that quality as well as quantity of tar deposits count. For some of the oils tested, the carbon residue of the used oils gave a better indication of ring sticking tendency. It also appears that a high viscosity rise as such is not necessarily detrimental from a ring sticking point of view, unless the engine condition favours considerable blow by.

The test plant was also used to investigate corrosion of bearing metals. For this purpose two of the connecting rod big-end bearings were fitted with the test metals and the engine operated at an elevated crankcase temperature $\left(320^{\circ} \mathrm{F}\right.$. by jacketing with hot air.

The results are stated to be in agreement with full-scale experiments.

The Determination of the Specific Heat of Gases at High Temperatures by the Sound Velocity Method. II-Carbon Dioxide. (G. G. Sherratt and E. Griffiths, Proc. Roy. Soc., Series A, Vol. I56, No. 889, 1/9/36, pp. 504517.) (2695 Great Britain.)

The principle of the method is the setting up of stationary sound waves at atmospheric pressure in a heated tube. The source of the wave system is a quartz crystal vibrating piezo-electrically. A movable reflector traverses the tube, points of resonance being determined by the sharply defined max. of the plate current of the oscillator operating the crystal. In this way the wave length and hence the velocity of sound can be determined, from which the specific heat values follow, using certain thermodynamic relationships. 'The experiments

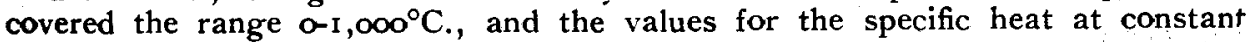


volume so obtained are in general above those given in the international critical tables.

\begin{tabular}{|c|c|c|}
\hline $\begin{array}{l}\text { Temp. } \\
0^{\circ}\end{array}$ & $\begin{array}{l}\text { Present Investigation } \\
6.62 \mathrm{cal} . / \mathrm{gm} \text {. mole. }\end{array}$ & $\begin{array}{c}\text { International Critical Tables } \\
6.63 \text { cal. } / \mathrm{gm} \text {. mole. }\end{array}$ \\
\hline $600^{\circ}$ & I 0.81 & 9.15 \\
\hline $1, \infty 0^{\circ}$ & I I. 76 & 10.17 \\
\hline
\end{tabular}

Purification of Exhaust Gases of Internal-Combustion Engines. (Chem. and Ind., Vol. 55, No. 37, I I $/ 9 / 36$, p. 820. British Patent No. 448,850.) (2714 Great Britain.)

The exhaust gases have different paths: (i) At low loads, (ii) at high loads. (i) May and (ii) must contain a purifier through which $\mathrm{O}_{2}$ is also passed, e.g., air is drawn sideways into a venturi throat.

Treatment of Exhaust Gases. (J. S. Kaufman, Chem. and Ind., Vol. 55, No. 37, I I $/ 9 / 36$, p. 820. U.S. Patent No. 2,02 I,690.) (27/5 Great Britain.)

The gases from some of the engine cylinders are cooled down and the $\mathrm{H}_{2} \mathrm{O}$ so obtained is brought in contact with $\mathrm{Fe}$ which is heated by the exhausts from the other cylinders. The resulting steam in the presence of iron oxide accelerates the oxidation of any $\mathrm{CO}$ present in the exhaust gas.

Lubrication Systems on Aero Engines. (German Patent No. 45I,217. Engineer, Vol. I62, No. 4209, I 1 $/ 9 / 3^{6}$, p. 275.) (2733 Germany.)

A centrifuge is driven by an extension of the supercharger shaft. The used oil passes outward on one side of the centrifuge disc and inwards on the other, re-entering the hollow crankshaft extension.

The casing of the centrifuge can be opened periodically to remove sludge.

Generation and Absorption of Gas in Insulating Oils Under the Influence of an Electric Discharge. (G. W. Nederbragt, J. Inst. Elec. Eng., Vol. 79, No. 477, Sept., 1936, pp. 282-290.) (2834 Great Britain.)

It is known that insulating oils may give off gas, chiefly hydrogen, under the influence of an electric discharge. This generation of gas is particularly marked in the case of oils which have been exhaustively refined to make them more resistant to oxidation. In this paper an attempt is made to discover to what extent the generation of gas of refined oils can be suppressed by the addition of relatively small quantities of aromatics. Insulating oils always have a more or less extensive boiling range. If it is desired to have a slight tendency to generate gas, with a relatively small percentage of aromatics, it is important that the aromatics present should correspond to the lowest boiling constituents.

Measurements of Flame, Velocity by a Modified Burner Method. (F. A. Smith and S. F. Pickering, Bur. Stan. J. Res., Vol. I7, No. I, July, 1936, pp. 7-43.) (2862 U.S.A.)

This paper describes a study of the application of the burner method to the determination of the velocity of propagation of flame relative to mixtures with air of various combustible gases.

Observations have been made on the effect of varying the size of the burner port, of changing the velocity of flow of the mixture from the burner, of changing the composition of the mixture, and of different methods of measuring the flame and computing the result. All of these factors relate to problems of gas utilisation.

Pulverised Fuel Engines. Latest Development in Germany. (D. Brownlie, Chem. and Ind., Vol. 55, No. 39, 25/9/36, pp. 745-746.) (2875 Germany.)

At the Darstadt meeting of the V.D.I., reference was made to a 200 b.h.p. single cylinder engine (I80 r.p.m.) operating on pulverised fuel. In order to prevent 
undue mechanical wear, it is important that the ash content of the fuel be very low. Finely divided carbonaceous fuel like flour and starch will operate satisfactorily. In the case of bituminous coal, an ash free fuel can be extracted by a solvent treatment with tetraline under pressure (Pott-Broche Process). Details of this are not available but a large plant is stated to be in process of erection.

Diesel Fuel Specifications. (C. H. Barton, Chem. and Ind., Vol. 55, No. 39, 25/9/36, p. 867.) (2876 Great Britain.)

The significance of the tests normally employed in fuel specifications is discussed. The essential tests for a Diesel fuel of petroleum origin are viscosity at $37.8^{\circ}$, or $5^{\circ} \mathrm{C}$. forming tendency, ignition quality. (for high-speed engines), ash, and $\mathrm{H}_{2} \mathrm{O}$. Pour point or viscosity at low temperature may be required in special circumstances.

Correlation of Tests in Ignition Quality of Diesel Fuels Carried Out at Delft and Sunbury. (G. D. Boerlage and others, Chem. and Ind., Vol. 55, No. 39, 25/9/36, p. 867.) (2877 Great Britain.)

Normal Diesel fuels, including cracked fuels can be rated in terms of suitable mineral secondaries in almost any type of Diesel engine without serious risk that large differences will be found between one engine and another.

Modern Testing of Motor Fuels for the High-Speed Type of Diesel Engine. (A. Hagemann and T. Hammerich, Chem. and Ind., Vol. 55, No. 39, 25/9/36, p. 867.$)$ (2878 Great Britain.)

In addition to the usual tests for Diesel oils, methods have been developed for filtering ability (difference in time of flow of $200 \mathrm{ml}$. of oil through a special apparatus, with and without a gauze filter), corrosion (of $\mathrm{Cu}$ and $\mathrm{Zn}$ ), ignitability (using a single-cylinder Deutz engine), and coking properties (determining the asphalt and coke on a sample after heating at $155^{\circ}$ in a bomb under 200atm. air pressure). The effect of the fuel on the smoking point of the engine is important, but no satisfactory method for determining the latter point has been described. (See also Abstract No. 39/93).

Oil Oxidation. (R. W. Dornte and C. V. Ferguson, Chem. and Ind., Vol. 55, No. 39, 25/9/36, p. 867.) (2879 Great Britain.)

The oxidation of lubricating oils (unaffected by the reaction products) is approximately proportional to the partial pressure $\mathrm{O}_{2}, \mathrm{H}_{2} \mathrm{O}$ and $\mathrm{CO}_{2}$ but no peroxides are formed and inhibitors are practically without effect. $\mathrm{Cu}$ increases considerably the rate of oxidation but $\mathrm{Fe}, \mathrm{Sn}$ and $\mathrm{Pb}$ have only a slight accelerating influence.

Precision Attainable in Knock Rating of Fuels for Internal-Combustion Engines. (J. Frank. Inst., Vol. 222, No. 3, Sept., I936, pp. 365-366.) (2887 U.S.A.)

From an analysis of 2,180 tests carried out on 99 fuels, the Bureau of Standards concludes that the probable error for the average of these fuels is less than $\frac{1}{2}$ octane No. The precision of rating is nearly the same for straight run petrols, blends of straight run and cracked and for leaded fuel of any base.

The error is greater for non-leaded cracked fuels and benzol blends. The octane number depends in some cases on atmospheric humidity. Accuracy is thus improved by air conditioning as well as by limiting the period between overhauls to 5o hours.

In all cases it is important that the knock intensity be kept constant throughout the tests. 
Bromine, Plant of Ethyl-Dow Chemical Co. (J. Frank. Inst., Vol. 222, No. 3, Sept., 1936, p. $3^{88 .)}$ (2889 U.S.A.)

During the $2 \frac{1}{2}$ years of operation, the plant has extracted 10.000 tons of Bromine from sea water. (Weight of water treated app. $130 \times 10^{6}$ tons).

Most of this Bromine has been used in the preparation of Ethyl Fluid.

A Differential Thermoscope. (G: Rempp, Comp. Rend., Vol. 202, No. 23, 8/6/36, pp. 1937-1939.) (1805 France.)

The author proposes to adapt the cooling meter of Thilenius (Met. Zeit., Vol. 48, I93I, p. 254.) so as to record small wind speeds. For this purpose two identical recipients made of polished copper and connected by means of a manometer, are exposed to the wind. An electric heater is incorporated in the wall of one of the vessels and the heating circuit is broken when the temperature difference between the two vessels (as recorded by the manometer) reaches a definite value. The current is similarly re-established when the temperature difference has fallen a prescribed amount.

The quantity of electricity required is a measure of the cooling effect. This in its turn can be linked up with the strength of the wind, by means of a suitable calibration.

Electric Pressure Recording Device. (A. Hasse, Z.V.D.I., Vol. 80, No. I9, 9/5/36, pp. 563-564.) (2043 Germany.)

An electric condenser is built up of three plates, the dielectric (air) being pressure sealed. Variation of external air pressure causes small movements of the outer plates (I/100 to $\mathrm{I} / \mathrm{I}$ c00 $\mathrm{mm}$.) and thus varies the electric capacity. A single valve amplifying circuit is described which gives variation of capacity directly on a sensitive current indicator. The dimensions of the condensor are kept small (2-3 $\mathrm{mm}$. diameter) and rapidly varying pressures $(1000 / \mathrm{sec}$.) can be recorded on an oscillograph, the available current being of the order of $\mathrm{ro}^{-3} \mathrm{~A}$ for $\mathrm{I} / \mathrm{roo}$ $\mathrm{mm}$. water gauge. The instrument is principally intended for accurate altitude measurements, the sensitivity being of the order of $\mathrm{r} \mathrm{m}$. for altitudes between o and $250 \mathrm{~m}$. By altering the electric constants of the circuit, greater altitudes can be recorded.

Time Lag in a Control System. (A. Callender and others, Phil. Trans. Roy. Soc., Vol. 235, No. 756, $21 / 7 / 36$.) (239r Great Britain.)

The "law of control," or relation between the behaviour of the quantity to be controlled and the effect (after the expiration of the time-lag) of the consequent control operation on it, is taken to be linear in the quantity controlled, its time derivative and time integral. For stable control the damping constants of all the normal modes must be positive and this, coupled with the requirement of quick return of the quantity controlled to its normal value after a disturbance, limits the practically useful range of values of the parameters in the law of control. A practical method, feasible on the industrial scale, for obtaining automatic control approximately in accordance with a law of control of the form here studied, is outlined, and two analogous methods are indicated.

Joliet Reference Gas Meter. (H. S. Bean and others, Bur. Stan. J. Res., Vol. I7, No. 2, August, 1936, pp. 207-246.) (2836 U.S.A.)

The meter is of the proportional type in which the main gas stream is divided into a large and a small stream, the latter being measured directly by means of a piston meter.

The actual ratio of the mass rates of the two gas streams is determined by a thermal method. Two heat exchangers, one in each gas stream, receive heat through the medium of hot water from a common source. The rates of flow of the 
hot water to the two heat exchangers are adjusted until the temperatures of the outlet water streams are the same.

The rates of flow of the gas in the two streams are then adjusted to bring together their temperatures on the outlet side of the heat exchangers. The ratio of the mass rates of flow of the gas streams is now equal to the ratio of the mass rates of flow of the water streams.

The latter can be readily measured by weighing and since the rate of flow of the small gas stream is known from the piston meter the main flow can be calculated.

The New R.C.A. Radio Compass. (Aero Digest., Vol. 29, No. 2, Aug., 1936, pp. 38-40.) (2421 U.S.A.)

The new type A.V.R. 8 weighs $20 \mathrm{~kg}$. and is operated by a $2 \mathrm{v}$. battery.

The circular antenna is $20 \mathrm{~cm}$. diameter and housed in a streamline case.

The radio compass gives simultaneous optical and acoustic indications.

The ro valve superhet receiver ensures telephone communication (weather news) simultaneously with direction finding.

An installation diagram is given.

The Petoscope: A New Principle in Photo-Electric Applications. (A. S: Fitzgerald, J. Frank. Inst., Vol. 222, No. 3, Sept., 1936, pp. 289-325.) (2884 U.S.A.)

The object is viewed by means of two photocells, the light having to pass through two fine meshed grids one being placed in front of each cell. If the dimensions of the object are comparable with the spacing in each grid, a displacement of the object relating to the background will cause an alternating stimulation of the cells, the frequency of the alteration depending on the velocity of movement, the distance of the object and the dimension of the grid divisions. A change in illumination will, however, cause no pulsation.

By using suitable amplification, extreme sensitivity and stability can be combined. The apparatus will detect the passage of aircraft at altitude up to 2,000 feet from the ground. Other possible applications are described.

The Consumption of Energy and the Production of Heat in a Vibrating Steel Bar. (A. Ono, Z.A.M.M., Vol. 16, No. I, Feb., 1936, pp. 23-32.) (1731 Germany.)

The author has measured the mechanical energy employed and the heat produced, in the flexural and torsional vibrations of a steel bar. After describing the apparatus for measuring the vibrations and the method for calculating the conduction of heat, he indicates and analyses the results of his experiments. He shows in particular, that the stationary state of motion, where the energy employed equals the heat produced, is reached only after a considerable number of vibrations.

On the Buckling of a Curved Rod. (A. Lockschin, Z.A.M.M., Vol. I6, No. I, Feb., 1936, pp. 49-55.) (1734 Germany.)

Setting out from the general differential equations and boundary conditions of the problem, the author integrates them in some special cases by the method of Adams-Störmer and finds the buckling load by calculating the first characteristic value.

Concerning a New Method of Obtaining Highly Polished Metallic Surfaces. (P. Jacquet, Comp. Rend., Vol. 2oI, No. 27, 30/12/35, pp. 1473-1475.) (1938 France.)

So far the method only applies to copper and some of its alloys. The article requiring polishing is made the anode, the cathode being a plate of copper of slightly larger dimensions. The electrolyte consists of an aqueous solution or 
ortho or pyrophosphoric acid. Over a certain limited range of applied voltage and current density, the surface of the anode facing the cathode becomes shiny, the surface being superior to that obtainable by ordinary polishing.

Treated Fabrics for Oil Pump Diaphragms. (U.S.A. Patent No. 2,04I,836. Chem. Absts., Vol. 30, No. 14, 20/7/36, p. 5026.) (2308 U.S.A.)

A fabric such as a mercerised cotton cloth is impregnated with a drying oil such as linseed oil containing $0.25^{-2}$.o per cent. of a polyaryl guanidine, phenyla-naphthylamine, $p$-hydroxydiphenyl, catechol, a-naphthol or creosol, and then dried.

Stiffness in Stressed Skins. (E. H. Atkin, Airc. Eng., Vol. 8, No. 9o, August, 1936, pp. 213-217.) (2337 Great Britain.)

Many types of stiffened skin constructions require stringers at such a pitch that the structure is not acting as a tension diagonal system. The presence of residual compression reduces the loading on the booms or other boundary members. This limits the application of the Wagner tension diagonal theory.

The complete rational solution of the problem is difficult and the author offers his investigation as an intermediate step which enables quantitative predictions to be made in certain cases.

Fabric in Shear. (Airc. Eng., Vol. 8, No. 90, August, 1936, pp. 227-228.) (2342 Great Britain.)

This is an instructive experiment in connection with the theory of thin sheets in spar webs.

According to the Wagner theory, the shear is carried by a diagonal tension stress combined with a compressive stress in vertical stiffeners.

In a normal spar web, the shear load is carried by a shear stress in the web which may be stiffened to prevent buckling.

A test piece was made up using fabric as a material for the web of the spar which has no resistance to buckling but a good strength in tension.

Experiments showed that the structure failed at an average stress of $48 \mathrm{lb}$. per inch width of fabric.

The tensile strength of the aircraft fabric used should have been 8 olb. per inch width.

The difference may be partly accounted for by the lie of the threads not coinciding with the direction of the tension diagonals.

The change in appearance with increase in load of the web from an even wrinkling over its surface to a generally flat surface with deep wrinkles at the end of the stiffeners may indicate the necessity of careful design in a real spar at this point.

On an Experimental Method for the Solution of Plane Stress Problems. (L. Chitty and A. J. S. Pippard, Proc. Roy. Soc., Series A, Vol. 156, No. 889, I/9/36, pp. $5^{\text {I } 8-537 .) ~(2696 ~ G r e a t ~ B r i t a i n .) ~}$

The model is made of thin rubber sheet, floating on mercury. It is held and loaded according to the nature of the problems under investigation, any tendency to buckle being prevented by placing small weights on the surface.

The displacements under load of selected points on the surface are measured by means of a micrometer microscope. From the slope of these curves, the stresses can be calculated, using the elastic properties of the rubber as previously determined. The method was applied to the study of a disc supported on a central hub and loaded radially over a small arc. This problem was studied 
theoretically by the authors (Phil. Mag., Vol. 21, No. 138, Jan., 1936, p. 106) and the experimental agreement is good.

It is hoped that further development in technique will make the method useful for obtaining stress distribution in cases not amenable to mathematical analysis.

Improvements Relating to Aircraft Wing Covering. (French Patent No. 765,347 . L'Aéronautique, Vol. I8, No. 206, July, 1936, p. 96.) (2817 France.)

A shell construction for wings, is proposed using neither ribs nor spars. The material consists of compressed cork which is glued between two layers of metal or plywood, the outer surface being sprayed with a layer of aluminium. The shear resistance of the cork exceeds $\mathrm{I} \mathrm{kg} \cdot / \mathrm{cm} .{ }^{2}$. The principal advantage claimed is high internal damping against vibrations.

Corrosion Behaviour of Painted Iron and Inhibitive Action of Paints. (R. M. Burns and H. E. Haring, Bell Tele. Pubs. No. 928, 1936.) (2833 U.S.A.)

The corrosion behaviour of bare iron can be determined by measurements of its potential and change in potential time. With the aid of a vacuum tube electrometer this method of study has been extended to the determination of the corrosion behaviour of painted iron and the mechanism of the inhibitive action of paints. Red oxide $\left(\mathrm{Fe}_{2} \mathrm{O}_{3}\right)$ and red lead $\left(\mathrm{Pb}_{3} \mathrm{O}_{4}\right)$ have been studied both as pigments and primers. The validity of the method has been demonstrated by the fact that it confirms conclusions which have been obtained only after many years of practical experience, i.e., that the corrosion inhibitive action of red oxide primer is purely physical, while that of red lead is essentially chemical. Both types of protective paint may maintain iron in the passive condition ; the former by keeping the iron dry, the latter by chemically passivating it in the presence of moisture.

Determination of the Brinell Number of Metals. (S. N. Petrenko and others, Bur. Stan. J. Res., Vol. I7, No. I, July, 1936, pp. 59-95.) (2863 U.S.A.)

The procedure used in making Brinell tests must be closely controlled in order that two observers testing a given metal at different locations should obtain Brinell numbers that are in close accord. Small variations in testing procedure will be inevitable so that it becomes important to know the effect of these variations on the magnitude of the Brinell number obtained. The present paper considers the effect on the Brinell number of such variation with the help of data available in the literature supplemented by new tests wherever the existing data seemed deficient.

Fatigue Impact Testing Machine-Type Maybach-for Light Alloys. (R. Lante, Z. Metallk., Vol. 28, No. 8, August, 1936, pp. 233-236.) (2891 Germany.)

Previous testing machines measured the impact by the work done in $\mathrm{Kg} . \mathrm{cm}$. Such machines are sensitive to method of support, shape and rigidity of specimen, moreover the testing time is rather long. In the Maybach apparatus described, a cylindrical test piece $9 \mathrm{~mm}$. in diameter and $150 \mathrm{~mm}$. long is supported at its ends and subjected to simultaneous impact of 2 cams operating at $70 \mathrm{~mm}$. from each end. The advantage of this machine is that the impact loading can be measured in $\mathrm{kg} . / \mathrm{mm} .^{2}$ 6o to 80 blows per second can be given and time of experiment is restricted.

The Temperature of Atmospheric Ozone. (M. J. Devaux, Comp. Rend., Vol. 201, No. 27, 30/12/35, pp. I 500-1 501.) (I934 France.)

The temperature was estimated from a study of the infra-red spectra of the sky obtained at the observatory of Pic du Midi (altitude $2,860 \mathrm{~m}$.). From the intensity of the absorption band at $10 \rho$, it is estimated that the ozone belt is at an average temperature considerably below $\mathrm{O}^{\circ} \mathrm{C}$ and does not undergo any marked diurnal or seasonal variations. 
The Physiology of the Aviator. (G. Schubert, Rev. de 1'Arm. de 1'Air, No. 85, Aug., 1936, pp. 953-958.) (2883 Germany.)

The French reviewer of this medical book hails it as the standard reference work for every doctor. Of special interest are the chapters dealing with acrobatic and high altitude flying. The maximum acceleration which can be supported by the trained individual is $5 \mathrm{~g}$. (head to feet) but only $2 \frac{1}{2} \mathrm{~g}$. (feet to head). The amount of blood in circulation increases with height but is unlikely to produce heart stressing.

The importance of the labyrinth in giving the pilot "air sense" is discussed.

It appears that modern medical research will influence present day regulations for the acceptance and supervision of pilots.

Carbon Monoxide Indicator for Aircraft. (J. Frank. Inst., Vol. 222, No. 3, Sept., 1936, pp. 366-367.) (2888 U.S.A.)

The maximum amount of $\mathrm{CO}$ in air to which a person may be exposed without harm for one hour is .04 per cent at ground level and less at altitude.

As risk of $\mathrm{CO}$ pollution exists in aircraft cockpits (either from leaks in exhaust pipe or inflow of exhaust gases by air currents), the Bureau of Standards have modified commercial $\mathrm{CO}$ indicators to make them available for aircraft. An alarm has been developed which sounds if the CO concentration exceeds .o2 per cent. A full description is given in N.A.C.A. Tech. Note No. 573 .

High Speed Photography. (H. E. Edgerton and others, Sci. Absts. (Section B), Vol. 39, No. 462, 29/6/36, p. 383. Phot. J., 76, pp. 198-204, April, 1936.) (I90I Great Britain.)

The authors briefly describe a method of high-speed photography developed for the study of oscillations of synchronous motors following changes in load and during the transient period of the motor as it endeavours to pull into synchronism. The control of the illumination, which is obtained from discharge tubes, is by means of electronic amplifiers, these consisting of a condenser, induction coil and grid-controlled mercury-arc rectifier. The grid of the rectifier is actuated by a commutator on the camera, thereby spacing the pictures correctly. A speed of $\mathrm{r}, 200$ pictures per sec. is obtained with full-frame $35 \mathrm{~mm}$. pictures, capable of increase up to 6,000 per sec. by reducing the frame size.

The Thermal Conduction of Glycerine Water Mixtures. (S. Erk and A. Keller, Phys. Zeit., Vol. 37, No. 10, 15/5/36, pp. 353-358.) (i 723 Germany.)

Model experiments on heat transfer (law of similarity) require the knowledge of the thermal conductivity of the fluid. This has generally restricted the experimenter to the use of water, since only for this fluid are the physical constants known with sufficient accuracy. Unfortunately the viscosity of water is considerably less than that of most fluids of interest to the heat engineer. This renders convection phenomena difficult to reproduce. For this reason the authors have determined the thermal conductivity of glycerine-water mixtures at temperatures varying from 7 to $70^{\circ} \mathrm{C}$. The glycerine content varied from o to 100 per cent. and the estimated accuracy of the conductivity is \pm 2 per cent.

(See also O. K. Bates, Ind. and Eng. Chem., Vol. 28, No. 4, April, 1936, pp. 493-498).

Short Wave Phase Measurements for Blind Landing. (K. Bärner, Sci. Absts. (Section B), Vol. 39, No. 461, 25/5/36, p. 329; from Hochfrequenztechn u. Elektroakustik, 47, Feb., 1936, pp. 45-55.) (I686 Germany.)

The author investigates the possibility of using phase measurements at very high frequencies, of the order of $10-20 \mathrm{~m}$. wave-length, as a means of ascertain- 
ing small heights above the ground for the blind landing of aircraft. An open oscillator was used which could be elevated above the ground from a tower. The phase-measuring circuit consists of 2 valves in push-pull. A comprehensive series of curves relate the phase of the current with height and wave-lengths, for different types of open oscillatory circuits. The effect of reflections from the earth, giving interference effects, is evident, and is considered by the author.

Micro-Ray Communication. (W. L. McPherson and E. H. Ullrich, J. Inșt. Elec. Eng., Vol. 78, No. 474, June, 1936, pp. 629-657. Discussion, pp. $65^{8-667-52}$ references.) (I74I Great Britain.)

This excellent paper starts with a short historical review of the evolution of wireless communication. The method of generation and modulation of micro-rays around $17 \mathrm{~cm}$. with a tube having two grid lead-outs is discussed, and it is argued that the grid itself becomes a transmission line of negative leakance. Some experiments with ebonite lenses and zone plates are described. Paraboloidal mirrors, echelon gratings, and hemispherical mirrors, are discussed.

The micro-ray equipments used on the commercial Lympne-St. Inglevert and the experimental Escalles-St. Margaret's links are described. Propagation measurements on these last two links are detailed and it is shown that, although there is an optical path in each case, severe fading, which is different on different wavelengths, sometimes takes place. This fading is attributed to an interference pattern which varies with atmospheric and tidal changes.

The directivity and gain by using paraboloidal mirrors and echelon gratings, as determined by experiment, are given.

In conclusion, future possible uses of micro-rays are sketched.

The extremely small size of aerial required would render micro-waves especially suited for aircraft communication. Difficulties arise, however, from reflection of the waves by the metal (or metallised) parts of the structure.

High Speed Electric Motors. (R. C. Colwell and N. I. Hall, J. Frank. Inst., Vol. 22 I, No. 6, June, 1936, pp. 797-805.) (1 $78_{3}$ U.S.A.)

In this paper, two new types of electric motors are discussed which are capable of rotating 100,000 r.p.m. A synchronous motor is described but the emphasis is placed upon the new design of the induction motor. This motor is mounted upon a single bearing and for high speeds must be run in a vacuum.

The high frequency current (3,00o r.p.s.) is produced from a two phase Alexanderson alternator, which is described. The circuit of this alternator must be tuned to resonance. The velocity of the rotating motor is measured with a new type of Stroboscope which has a wide range of values and is easily calibrated.

Aluminium alloys for the discs and commercial bearings have been tested and found suitable for speeds up to 75 , 000 r.p.m.

A Method of Improving the Efficiency of Electrostatic Motors. (P. Jolivet, Comp. Rend., Vol. 202, No. 25, 22/6/36, pp. 2051-2052.) (1940 France.)

Reference is made to the electro-static generator described previously (see abstract, Abstracts and Notices No. $3^{8}$, item 151 ).

By enclosing the motor in an airtight chamber both the supply voltage and the power output increase with increased air pressure.

At a constant speed of rotation (30o r.p.m.) the power output of this particular motor (10 $\mathrm{cm}$. plate weighing $20 \mathrm{gm}$.) rose from $0.37 \mathrm{watts}$ (atmospheric pressure) to 2.84 watts $(4.5$ atmospheric absolute). At this output, the efficiency exceeded 40 per cent. 
Rain Static. (H. K. Morgan, Proc. Inst. Rad. Eng., Vol. 24, No. 7, July, 1936, pp. 959-963.) (2039 U.S.A.)

The problem of rain static, particularly as it affects aircraft is treated. Rain static is due to particles of rain, snow, or dust striking aircraft antennas. It has been found that the disturbance is electrostatic in origin and that an electrostatically shielded loop antenna reduces it materially.

High Voltage Mercury-Pool Tube Rectifiers. (C. B. Foos and W. Lattemann, Proc. Inst. Rad. Eng., Vol. 24, No. 7, July, 1936, pp. 977-984.) (2040 U.S.A.)

Mercury-pool tubes of the ignition type offer attractive features for power rectifier service. This paper discusses the application of this type to controlled high voltage, high power rectifiers to radio transmission, and some problems peculiar to their use as such. An experimental rectifier of this type, which has been in operation, is described.

Ionosphere Studies during Rartial Solar Eclipse of February 3, 1935. (S. S. Kirby and others, Proc. Inst. Rad. Eng., Vol. 24, No. 7, July, 1936, pp. 1027-1040.) (204I U.S.A.)

Virtual height and critical frequency measurements of the several regions of the ionosphere were made during the day of the solar eclipse of February 3, 1935, and during several days before and after the eclipse day. The eclipse was found to produce a decrease of the critical frequency of each region. The decrease of critical frequency was approximately in time phase with the eclipse, thus indicating an ionising agency (probably ultra-violet light), originating in the sun and propagated at approximately the velocity of light.

A New Electron Tube having Negative Resistance. (J. Groskowski, Proc. Inst.

Rad. Eng., Vol. 24, No. 7, July, 1936, pp. 104I-1052.) (2042 Poland.)

The dynatronic and magnedynatronic systems commonly used to obtain a negative resistance by means of triodes or tetrodes are characterised by the fact that the potential of the active electrode (the anode) is not the highest potential in the system; an electrode (the grid or the screen grid) at a higher potential is necessary in order to take off the secondary emission current from the anode in such a way that a falling characteristic is produced in the anode circuit.

The present paper deals with a three-electrode tube of such design that the negative resistance is obtained in the circuit of the electrode possessing the highest potential in the system.

Preventing Collisions in the Air. An American Radiaura. (Aeroplane, Vol. 5I, No. I $315,5 / 8 / 3^{6}$, p. 177 , and 1316, 12/8/36, pp. 212-213.) (2505/2323 Great Britain.)

Both instruments utilise the cathode ray tube.

(I) English Construction.

The proximity' of a sending station is recorded by the lengthening of a luminous line on the screen of the cathode ray tube. Two fixed ring antennx at right angles are employed.

(2) American Construction (U.S. Coast Service).

A fixed and a movable antenna are joined via amplifiers to the deflecting plates of the cathode tube.

When approaching transmitting station a vertical line is seen on the screen. Deviation, of course, is shown by inclination of line to right or left. 
Closer proximity to the home station is indicated by the appearance of an ellipse or circle on the screen. Vertically above the transmitting station a single dot is recorded.

With a $50 \mathrm{kw}$. transmitter, the range is 200 to $300 \mathrm{~km}$.

Technical Details of the Television Sending Station of the Eiffel Tower (Paris).

(J. Le Duc and R. Bärthélemy, Revue Générale de l'Electricité, Vol. 39, No. $18,2 / 5 / 3^{6}$, pp. 651-66r.) (2589 France.)

Details are given of the studio, the machinery installation and the antenna. The studio is situated at some distance from the Eiffel Tower and this necessitated a cable $2,000 \mathrm{~m}$. leading to the machinery hall. A feeder cable, $320 \mathrm{~m}$. long, leads from this to the antenna proper situated near the top of the tower. The transmission is on a wave length of $8 \mathrm{~m}$., the radiated energy being of the order of $\mathrm{I} \mathrm{kw}$. (supplied energy $=2.5 \mathrm{kw}$.). The image analysis is carried out with 180 lines (25 images per second).

Unlike the American system (Zworykin and Fainsworth) which is purely electronic, the system adopted on the Eiffel Tower is mechanical and largely based on experience gained with the 60 -line transmission ( $180 \mathrm{~m}$. wave length) already in regular use by the French Post Office.

The difficulties due to the stepping up in number of lines have been met by

(a) An improved spiral scanning disc with special obturator.

(b) Special photo-electric cells (gas filled).

The synchronisation system has already been described in a previous number (Revue Générale de l'Electricité, Vol. 38, 31/9/35, pp. 405-410). At the end of each analysing line a short signal is emitted in the inverse direction to thee brightness impulses. This signal only lasts I/I00 of the time, taken for the transmission of one picture line. Television pictures by this process are on view at a number of public places in Paris so that the public are kept in touch with developments. Attempts are being made to improve sensitivity of camera and reduce illumination of studio. At the present time the heat generated is such that very active ventilation is required in the studio and this in its turn introduces difficulties due to noise. It is hoped that a more efficient system (Io kw. radiated in antenna) will be available for the International Exhibition in 1937 .

Electrical Measurements at Wave Lengths Less than Two Metres. (L. S. Nergaard, Proc. Inst. Rad. Eng., Vol. 24, No. 9, Sept., 1936, pp. I 2071 229.$)$ (2828 U.S.A.)

In this paper the measurement of power and voltage at ultra-short waves is considered. A signal generator delivering adequate power output with satisfactory stability over the wave length from twenty to 200 centimetres is described. The requirements of thermocouples satisfactory for the measurement of power are considered and a set of thermocouples covering the power range from $o . I$ milliwatt to fifty watts is described. A study of vacuum tube voltmeters has shown that diode voltmeters have very small loading (of the order of $15^{\circ} \mathrm{ohms}$ ) on the circuits to which they are connected, whereas conventional triode voltmeters using RCA $-955^{15}$ have an input impedance of about $10^{4}$ ohms at a wave length of one metre. The errors of diode voltmeters at ultra-short wave lengths have been studied.

On the Anomalous Properties of Dielectrics. (J. Neufeld, J. Frank. Inst., Vol. 222, No. 3, Sept., 1936, pp. 327-336.) (2886 U.S.A.)

The causes of energy losses in dielectrics subjected to alternating stresses are not completely understood. One of the most satisfactory methods of treating 
these problems, due to von Schweidler, attributes the dielectric loss entirely to dielectric absorption. Some agreement between the methods of von Schweidler and experimental data has been found by F. Tank, J. B. Whitehead and R. R. Benedict. However, there does not exist a satisfactory test of the accuracy of the analysis of von Schweidler. The present paper gives :-

(I) A method of separating the losses due to absorption in dielectrics.

(2) A method for determining analytically the absorption curve of a dielectric in which hysteresis is absent.

(3) A graphical method of checking the accuracy of von Schweidler's analysis. 